\title{
Distributed Roughness Effects on Blunt-Body Transition and Turbulent Heating
}

\author{
Brian R. Hollis ${ }^{*}$ \\ NASA Langley Research Center, Hampton, VA 23681
}

\begin{abstract}
An experimental program has been conducted to obtain data on the effects of distributed surface roughness on blunt bodies. Sphere-cone and hemisphere geometry wind tunnel models with both pattern and sand-grain distributed surface roughness were tested at Mach 6 across a free stream Reynolds number range of $\operatorname{Re}_{\infty}=3.0 \times 10^{6} / \mathrm{ft}$ to $\operatorname{Re}_{\infty}=8.3 \times 10^{6} / \mathrm{ft}$. Laminar, transitional and turbulent surface heating data were obtained using global phosphor thermography. Roughness-augmented, turbulent heating levels from 1.0 to 1.9 times the predicted smooth-wall turbulent levels were measured.
\end{abstract}

\section{Nomenclature}

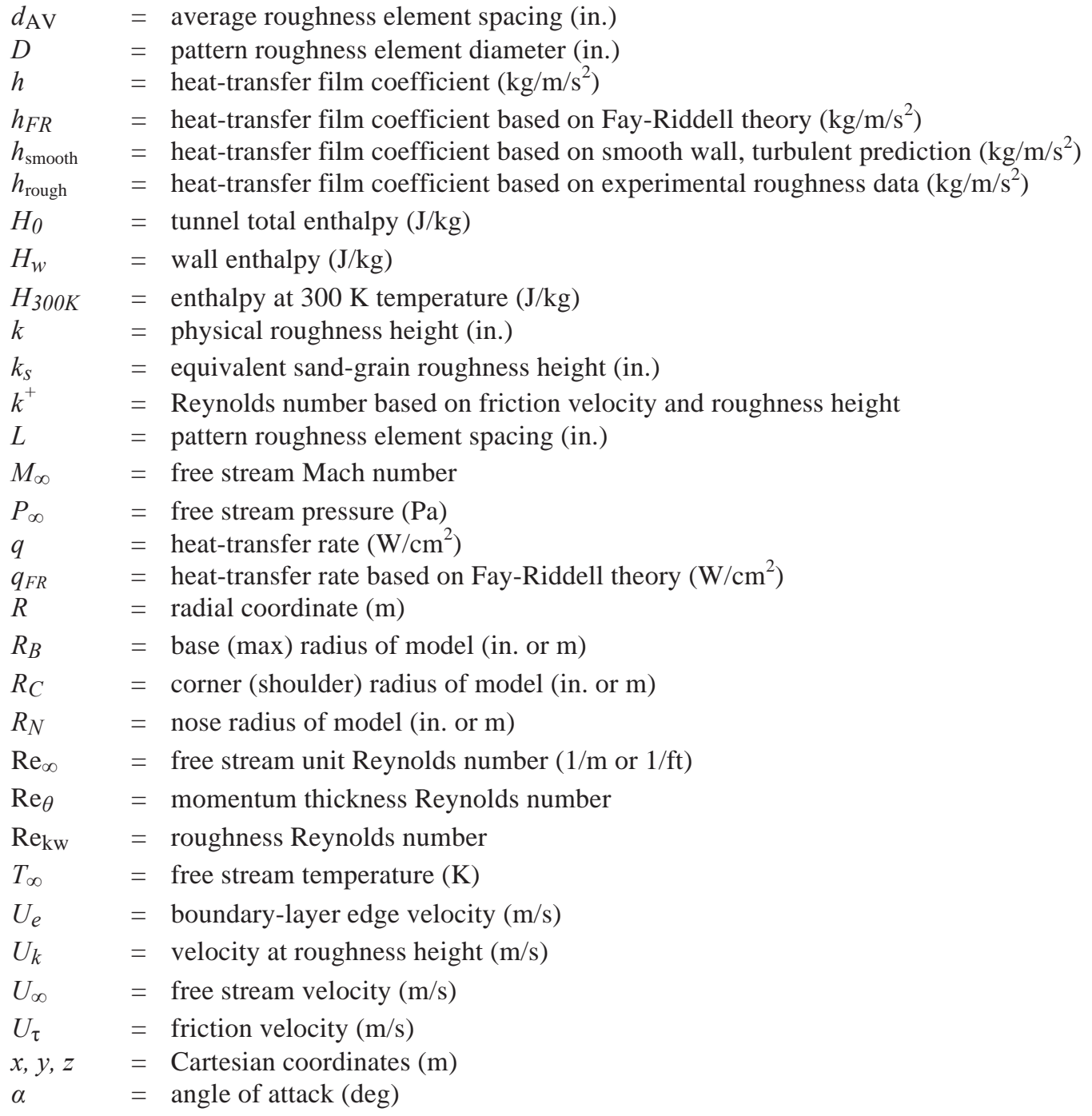

\footnotetext{
* AIAA Associate Fellow, Aerospace Engineer, Aerothermodynamics Branch, Research and Technology Directorate
} 


$\begin{array}{ll}\delta & =\text { boundary-layer height }(\mathrm{m}) \\ \theta_{\mathrm{c}} & =\text { sphere-cone model cone angle }(\mathrm{deg}) \\ \theta & =\text { momentum thickness }(\mathrm{m}) \\ \lambda & =\text { Dirling spacing parameter }(\mathrm{in} .) \\ \rho_{e} & =\text { boundary-layer edge density }\left(\mathrm{kg} / \mathrm{m}^{3}\right) \\ \rho_{k} & =\text { density at roughness height }\left(\mathrm{kg} / \mathrm{m}^{3}\right) \\ \rho_{w} & =\text { density at wall }\left(\mathrm{kg} / \mathrm{m}^{3}\right) \\ \rho_{\infty} & =\text { free stream density }\left(\mathrm{kg} / \mathrm{m}^{3}\right) \\ \mu_{e} & =\text { boundary-layer edge viscosity }(\mathrm{kg} / \mathrm{m} / \mathrm{s}) \\ \mu_{w} & =\text { wall viscosity }(\mathrm{kg} / \mathrm{m} / \mathrm{s}) \\ \tau & =\text { shear stress }(\mathrm{Pa})\end{array}$

\section{Background and Introduction}

In this work, the effects of surface roughness on boundary-layer transition and turbulent heating are considered. These effects are important because the surface roughness of an entry vehicle's Thermal Protection System (TPS) can promote earlier boundary-layer transition and produce higher turbulent heating (and shear) levels than would be expected based on an idealized, smooth-surface analysis. However, due to the complexities of roughness effects, a vehicle's TPS is typically designed using analytical, computational and/or experimental techniques that are based on the assumption of an Outer Mold Line (OML) with a smooth surface. The effects of roughness on the aerothermodynamic environment are then included through approximate engineering correlations and methods.

"Roughness" is a generic term in aerospace literature that can encompass different types of surface features, as illustrated in Table 1. Roughness can be divided into two general types: discrete and distributed. Discrete roughness includes surface features such as attachment-point cavities, compression pads, gaps or steps between heat-shield tiles and physical damage to a TPS. Distributed roughness includes features such as tightly-spaced TPS tile patterns or hexcombs and ablated TPS.

The historical database on discrete and distributed roughness effects (e.g. surveys presented in Refs. 1 and 2) has largely been built on the basis of ground testing of simple geometries such as hemispheres, flat-plates, and spherecones and from flight data on small-angle cones (e.g. missiles) and lifting bodies (e.g. the Space Shuttle). There are less data (especially for distributed roughness) available on blunt-body entry vehicles such as typified by the Apollo (spherical cap segment), Mars Science Laboratory (70-deg sphere-cone) or Genesis (60-deg sphere-cone) configurations.

To address the lack of distributed roughness data on blunt bodies, an experimental program has been conducted to obtain hypersonic wind tunnel data on the effects of distributed roughness on blunt bodies. Two blunt-body geometries were considered in the study: a 70-deg sphere-cone and a hemisphere. Two types of distributed roughness were employed: sand-grain and patterned. Data were obtained on these geometries to determine the effects of roughness on boundary-layer transition and turbulent heating augmentation and are presented herein.

Table 1. Surface roughness types

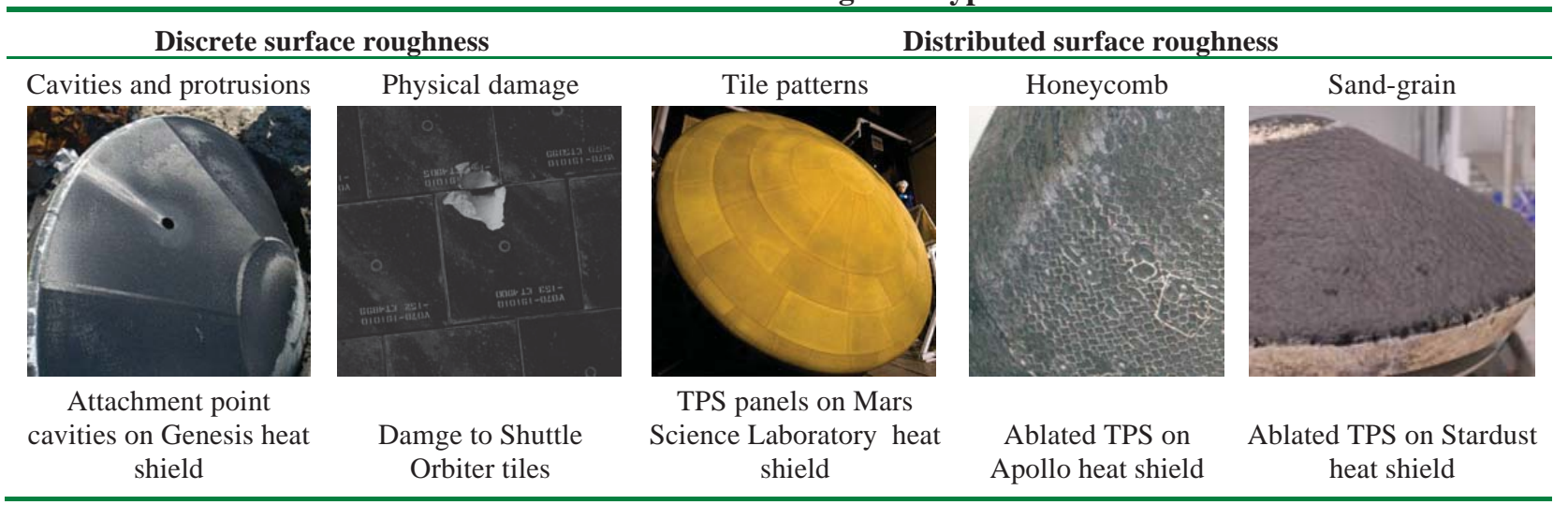




\section{Test Program}

\section{A. Experimental Facility}

Testing was performed in the NASA Langley Research Center (LaRC) 20-Inch Mach 6 Air Tunnel (Figure 1). This tunnel is a blow-down facility in which heated, dried, and filtered air is used as the test gas. A detailed description of this facility can be found in Ref. 3. The tunnel has a two-dimensional contoured nozzle that opens into a 20.5 in. $\times 20.0$ in. $(0.52 \mathrm{~m} \times 0.508 \mathrm{~m})$ test section. The tunnel is equipped with a bottom-mounted injection system that can transfer a model from the sheltered model box to the tunnel centerline in less than $0.5 \mathrm{sec}$. Run times of up to 15 minutes are possible in this facility, although for aeroheating studies run times of only a few seconds are typically required. The nominal reservoir conditions of this facility produce perfect-gas free-stream flows with Mach numbers between 5.8 and 6.1 and unit Reynolds numbers of $\operatorname{Re}_{\infty}=0.5 \times 10^{6} / \mathrm{ft}$ to $8.3 \times 10^{6} / \mathrm{ft}$ $\left(1.64 \times 10^{6} / \mathrm{m}\right.$ to $\left.27.4 \times 10^{6} / \mathrm{m}\right)$.

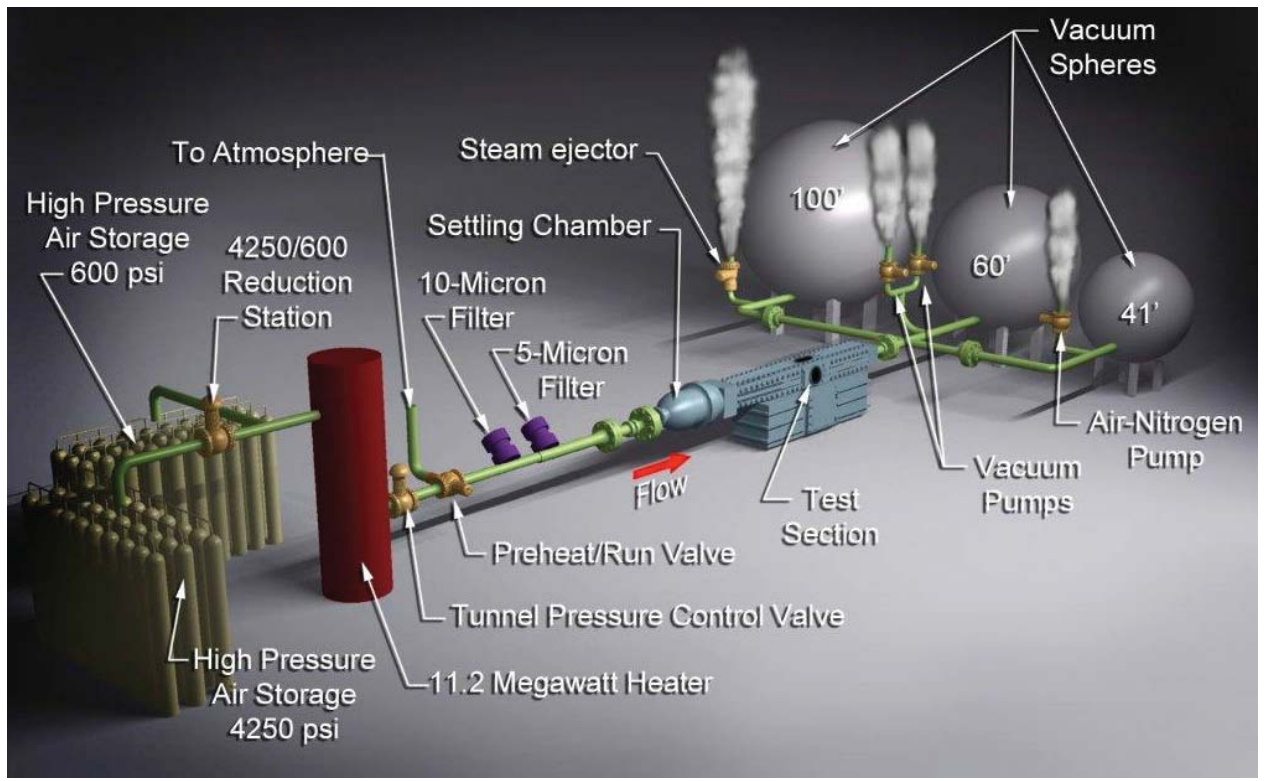

Figure 1. LaRC 20-Inch Mach 6 Air Tunnel

\section{B. Data Acquisition, Analysis and Uncertainty}

1. Phosphor Thermography

Convective aeroheating measurements were made using the two-color, relative-intensity, global thermographic phosphor method (Refs. 4-5). In this method, a ceramic model coated with a thermographic phosphor compound is illuminated by ultra-violet light sources that produce temperature-dependent fluorescence of the phosphor coating. Images of the model are taken in the tunnel before and during a run using a three-color, charge-coupled device camera. The fluorescent intensity data are converted to temperatures based on camera-response calibrations. Heattransfer rates are then determined with the assumption of a one-dimensional, step-function heating response (which corresponds to a parabolic temperature-time history) beginning at injection of the model into the tunnel.

The IHEAT (Imaging for Hypersonic Experimental Aerothermodynamic Testing) code is used to perform the data reduction. IHEAT provides global heat-transfer distributions expressed in terms of the ratio $h / h_{\mathrm{FR}}$, where $h_{\mathrm{FR}}$ is the heat-transfer coefficient resulting from a Fay-Riddell computation (Ref. 6) for the heat-transfer to a sphere of user-specified radius at cold-wall $(300 \mathrm{~K})$ conditions. Data are typically output as 2-D image files. Quantitative values can also be extracted from the image data along specific reference lines with geometric $(x-y)$ parameters that are approximately corrected through linear interpolation between user-specified reference locations.

\section{Three-Dimensional Data Mapping}

The image data produced by IHEAT are corrected for optical perspective effects and mapped to a threedimensional (3-D) surface model of the test article. To accomplish this mapping, iterative perspective, rotational, and translational transformations are performed on the 3-D surface geometry until its 2-D projection matches that of the 2-D image data. The image data are then assigned transformed $(x, y, z)$ coordinates based on interpolation 
between the image and surface geometry, and then the transformation is inverted to obtain a 3-D heating distribution. After mapping the image data to the 3-D surface geometry, direct comparison can be made to computational heating predictions.

\section{Data Uncertainty}

For testing of blunt-body configurations such as the in this study, an uncertainty estimate for the phosphor thermography measurement technique of approximately $\pm 10 \%$ can be made based on Ref. 5 . Uncertainties also are introduced through the variation of wind-tunnel flow conditions. Since the repeatability of flow conditions is very good, the resulting uncertainty in heating measurements is estimated to be only on the order of $\pm 5 \%$. The other major source of uncertainty that must be considered is the mapping of 2-D image data to a 3-D surface. This uncertainty is highly problem dependent; on the overall acreage of a blunt-body geometry, this uncertainty is estimated to be on the order of $\pm 10 \%$. However, in geometrically-complex regions, such as around small-scale features where the scale of such a feature approaches the resolution of the camera optics, this uncertainty could be higher. For this work, the acreage uncertainty of $10 \%$ is applied and resulting total uncertainty based on a rootmean-square summation of acreage mapping, flow conditions and measurement technique gives an estimate of $\pm 15 \%$.

\section{Roughness Model Design and Fabrication}

Three types of wind tunnel models were tested in this study: smooth-surface models, models with patterned surface roughness elements, and models with sand-grain surface roughness. Smooth models, pattern roughness and sand-grain roughness models were fabricated for the sphere-cone geometry, and smooth and sand-grain roughness models were fabricated for the hemisphere geometry. The pattern and sand-grain roughness sphere-cone models are shown in Figure 2 and Figure 3 and the hemisphere sand-grain roughness models are shown in Figure 4. The sphere-cone model diameter was 8-in. and the hemisphere diameter was 6-in; other geometry parameters are listed in Table 2. The model designation and fabrication process for each type of model is discussed below.

Table 2. Model geometry parameters

\begin{tabular}{cccccccccc}
\hline Model & $\begin{array}{c}\boldsymbol{R}_{\mathbf{B}} \\
(\mathbf{i n .})\end{array}$ & $\begin{array}{c}\boldsymbol{R}_{\mathrm{B}} \\
(\mathbf{m})\end{array}$ & $\begin{array}{c}\boldsymbol{R}_{\mathbf{N}} \\
(\mathbf{i n})\end{array}$ & $\begin{array}{c}\boldsymbol{R}_{\mathbf{N}} \\
(\mathbf{m})\end{array}$ & $\boldsymbol{R}_{\mathbf{N}} / \boldsymbol{R}_{\mathbf{B}}$ & $\boldsymbol{R}_{\mathbf{C}}(\mathbf{i n})$ & $\boldsymbol{R}_{\mathbf{C}}(\mathbf{m})$ & $\boldsymbol{R}_{\mathbf{C}} / \boldsymbol{R}_{\mathbf{B}}$ & $\begin{array}{c}\theta_{\mathrm{c}} \\
(\boldsymbol{d e g})\end{array}$ \\
\hline Sphere-cone & 4.00 & 0.1016 & 2.00 & 0.0508 & 0.500 & 0.200 & 0.00508 & .005 & 70 \\
Hemisphere & 3.00 & 0.0762 & 3.00 & 0.0762 & 1.000 & NA & NA & NA & NA \\
\hline
\end{tabular}
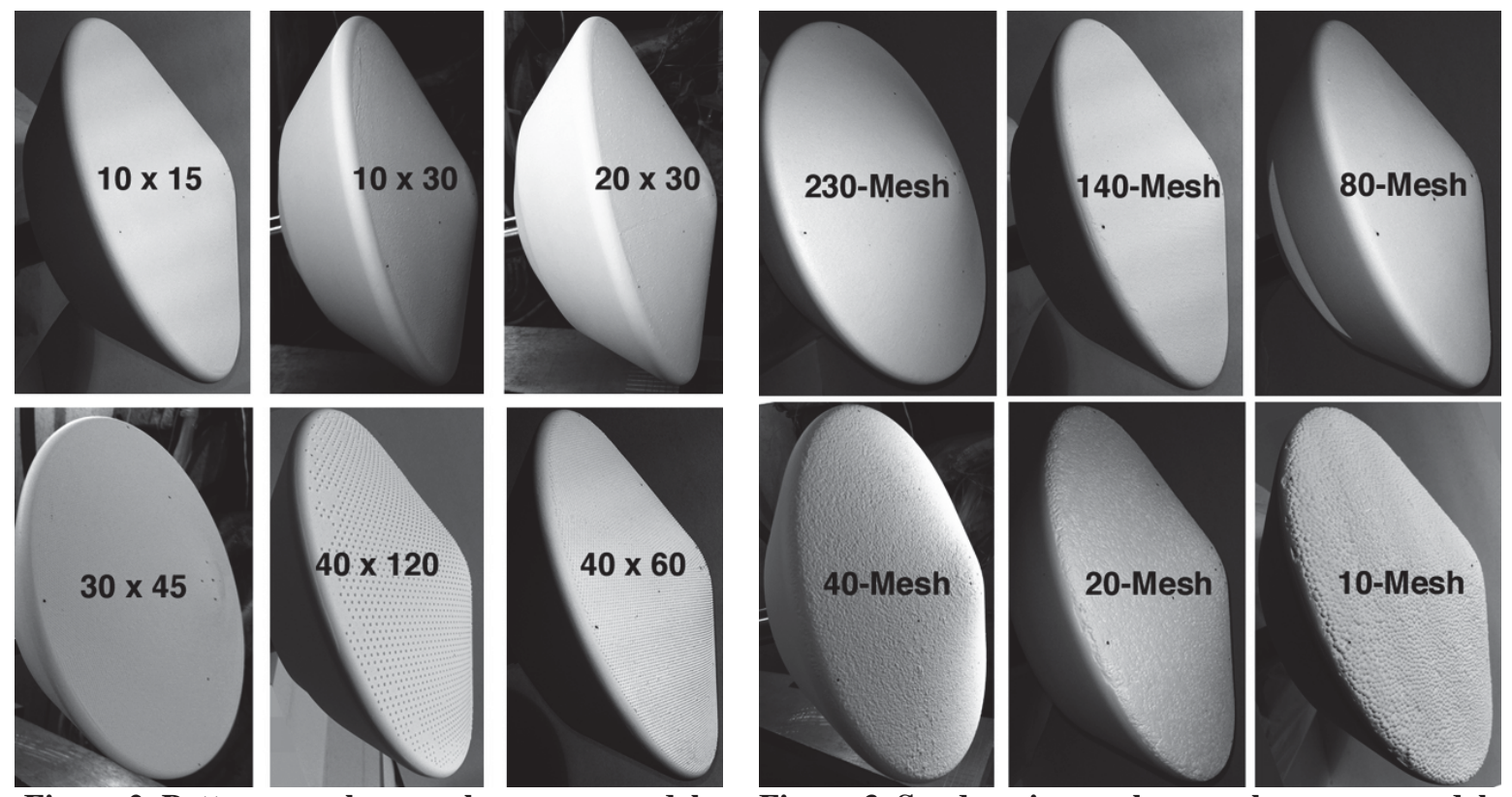

Figure 2. Pattern roughness sphere-cone models
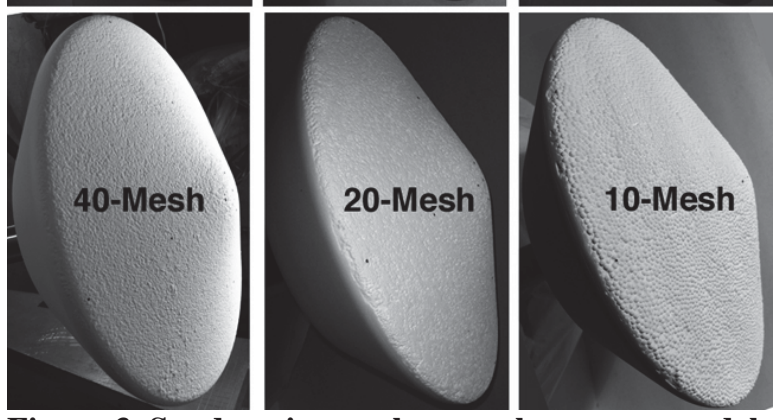

Figure 3. Sand-grain roughness sphere-cone models

4

American Institute of Aeronautics and Astronautics 

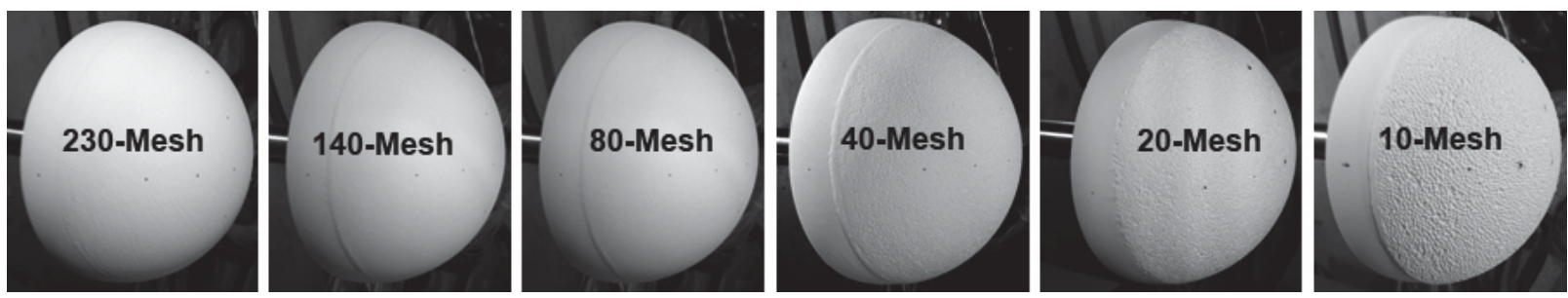

Figure 4. Sand-grain roughness hemisphere models

\section{Smooth-surface wind tunnel models}

Wind tunnel models for use with the phosphor thermography method are slip-cast in silica-ceramic and coated with a thermographic phosphor compound. The standard fabrication process (Ref. 7) begins with the production of a rapid-prototype, resin pattern of the geometry. The resin pattern is built in a stereo-lithographic apparatus (SLA) from a CAD data file. These patterns are then hand-worked to a smooth surface finish to remove any SLA manufacturing artifacts. A multiple-piece injection mold (from which the resin model can easily be removed) is then built around the resin pattern. The resin pattern is then removed and wax is injected into the mold to form a wax pattern. Next, a new two-piece shell mold is built around the wax pattern, and then the wax is burned out of the shell mold. A silica ceramic model is then slip-cast in the shell mold. Then, the ceramic model is removed from the shell mold, dried and sintered. The finished ceramic model is then back-filled with a hydraulically setting magnesia ceramic for strength and support. Finally, the model is coated with a mixture of phosphors that luminesce under ultraviolet lighting. This process was used to create smooth-surface models to serve as a baseline for comparison with roughness effects.

As a reference point for comparison with the roughness models, the surface roughness of the phosphor coating has been determined in previous measurements (Ref. 8) to be approximately 0.0005 in., which is below the range at which roughness effects on transition or heating would be expected. Turbulent data obtained in previous studies produced close comparisons between measured and predicted heating levels, which supports the conclusion that the phosphor surface roughness does not affect measured heating levels. The phosphor coating process does however, occasionally produce small, discrete surface features (on the order of 0.0015 in.) that can affect transition onset, but not cause heating augmentation. Similar effects can also sometimes be observed as a result of damage to the coating that occurs in small areas during handling and testing of the models.

\section{Patterned surface roughness wind tunnel models}

For the patterned surface models, metallic molds of the heat-shield surface were first fabricated in place of the SLA resin patterns. A chemical etching process was then employed to create hemispherical cavities of various diameters and spacings in the molds. Wax patterns were then created from the metallic molds and the rest of the fabrication process followed the same steps as for a standard, smooth-surface model. A metallic mold, ceramic model, and closeups of the roughness different roughness elements are shown in Figure 5.

The pattern roughness layout, also illustrated in Figure 5, consists of a repeated hexagonal array of hemispheres over the entire heat-shield surface of a model. The defining parameters of a pattern are the hemispherical element diameter, D, and the element center-to-center spacing L. Six pattern layouts were considered and the parameters are given in Table 3. The pattern name format is "DD x LL", where "DD" and "LL" are element diameter and spacing (both in inches) multiplied by 1000 and the wind tunnel models are identified by this pattern name. 


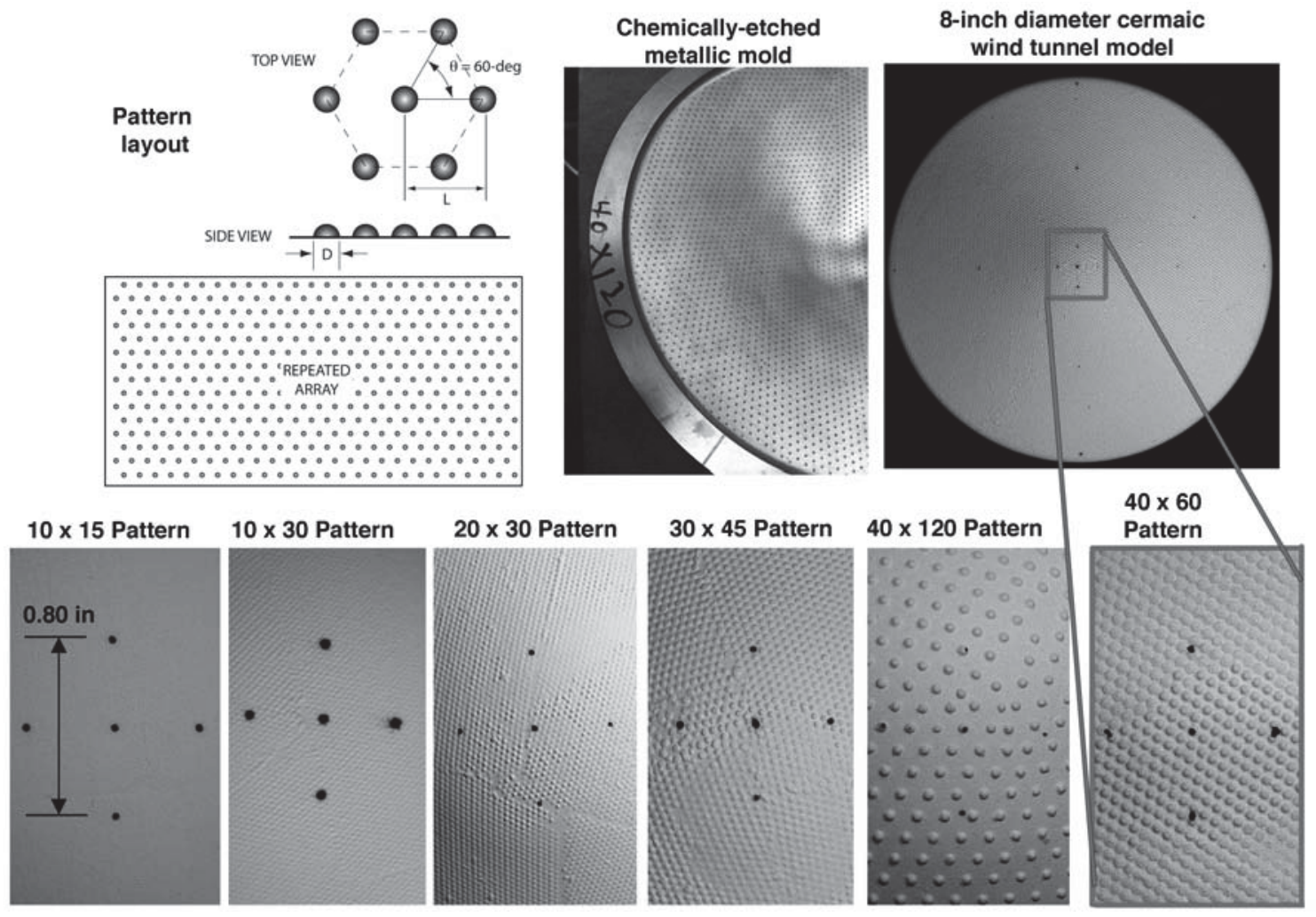

Figure 5. Pattern Roughness Layout

Table 3. Patterned surface roughness model parameters

\begin{tabular}{ccccccccccc}
\hline Pattern & Element & $\begin{array}{c}\boldsymbol{\lambda} \\
\text { (in.) }\end{array}$ & $\begin{array}{c}\boldsymbol{d}_{\mathbf{A V}} \\
\text { (in.) }\end{array}$ & $\begin{array}{c}\boldsymbol{D} \\
\text { (in.) }\end{array}$ & $\begin{array}{c}\boldsymbol{L} \\
\text { (in.) }\end{array}$ & $\begin{array}{c}\boldsymbol{k} \\
\text { (in.) }\end{array}$ & $\begin{array}{c}\boldsymbol{A}_{\mathbf{W S}} \\
\text { (in }^{2}\end{array}$ & $\begin{array}{c}\boldsymbol{A}_{\mathbf{P}} \\
\text { (in }^{2}\end{array}$ & $\boldsymbol{k}_{\mathbf{S}} / \boldsymbol{k}$ & $\begin{array}{c}\boldsymbol{k}_{\boldsymbol{s}} \\
\text { (in.) }\end{array}$ \\
\hline $10 \times 30$ & hemispherical & 14.07 & 0.0279 & 0.0100 & 0.030 & 0.0050 & $7.854 \mathrm{E}-05$ & $3.927 \mathrm{E}-05$ & 0.91 & 0.0046 \\
$10 \times 15$ & hemispherical & 7.03 & 0.0140 & 0.0100 & 0.015 & 0.0050 & $7.854 \mathrm{E}-05$ & $3.927 \mathrm{E}-05$ & 3.41 & 0.0171 \\
$40 \times 120$ & hemispherical & 14.07 & 0.1117 & 0.0400 & 0.120 & 0.0200 & $1.257 \mathrm{E}-03$ & $6.283 \mathrm{E}-04$ & 0.91 & 0.0183 \\
$20 \times 30$ & hemispherical & 7.03 & 0.0279 & 0.0200 & 0.030 & 0.0100 & $3.142 \mathrm{E}-04$ & $1.571 \mathrm{E}-04$ & 3.41 & 0.0341 \\
$30 \times 45$ & hemispherical & 7.03 & 0.0419 & 0.0300 & 0.045 & 0.0150 & $7.069 \mathrm{E}-04$ & $3.534 \mathrm{E}-04$ & 3.41 & 0.0512 \\
$40 \times 60$ & hemispherical & 7.03 & 0.0558 & 0.0400 & 0.040 & 0.0200 & $1.257 \mathrm{E}-03$ & $6.283 \mathrm{E}-04$ & 3.41 & 0.0683 \\
\hline
\end{tabular}

The equivalent sand-grain roughness heights, which are also listed in Table 3, are based on the theory developed by Dirling (Ref 9) to correlate pattern-type roughness data with sand-grain roughness data. The equivalent sandgrain roughness $k_{\mathrm{S}}$ is defined as

(1) $\frac{k_{s}}{k}=\left\{\begin{array}{c}0.0164 \times \lambda^{3.78}, \text { for } \lambda<4.93 \\ 139 \times \lambda^{(-1.90)}, \text { for } \lambda>4.93\end{array}\right.$ by

where the physical roughness $k$ is taken as $D / 2$ (the particle radius) and the Dirling spacing parameter $\lambda$ is given

(2) $\lambda=\left(\frac{d_{A V}}{k}\right)\left(\frac{A_{W S}}{A_{P}}\right)^{4 / 3}$

The wetted surface area $A_{\mathrm{Ws}}$ and profile area $A_{\mathrm{P}}$ for a hemispherical element are given by 
(3) $A_{W S}=\frac{1}{4}\left[4 \pi\left(\frac{D}{2}\right)^{2}\right]$

and

(4) $A_{P}=\frac{1}{2}\left[\pi\left(\frac{D}{2}\right)^{2}\right]$

and the average roughness element spacing $d_{\mathrm{AV}}$ for a hexagonal array is

(5)

$d_{A V}=\sqrt{\frac{\text { hexagonal area }}{\text { \# of elements }}}=\sqrt{\frac{\frac{3 \sqrt{3}}{2} L^{2}}{1+6 \times(1 / 3)}}=\sqrt{\frac{\sqrt{3} L^{2}}{2}}$

The functional relationship between equivalent sand-grain roughness and the Dirling spacing parameter is plotted in Figure 6. The resulting values for the sphere-cone models are also shown.

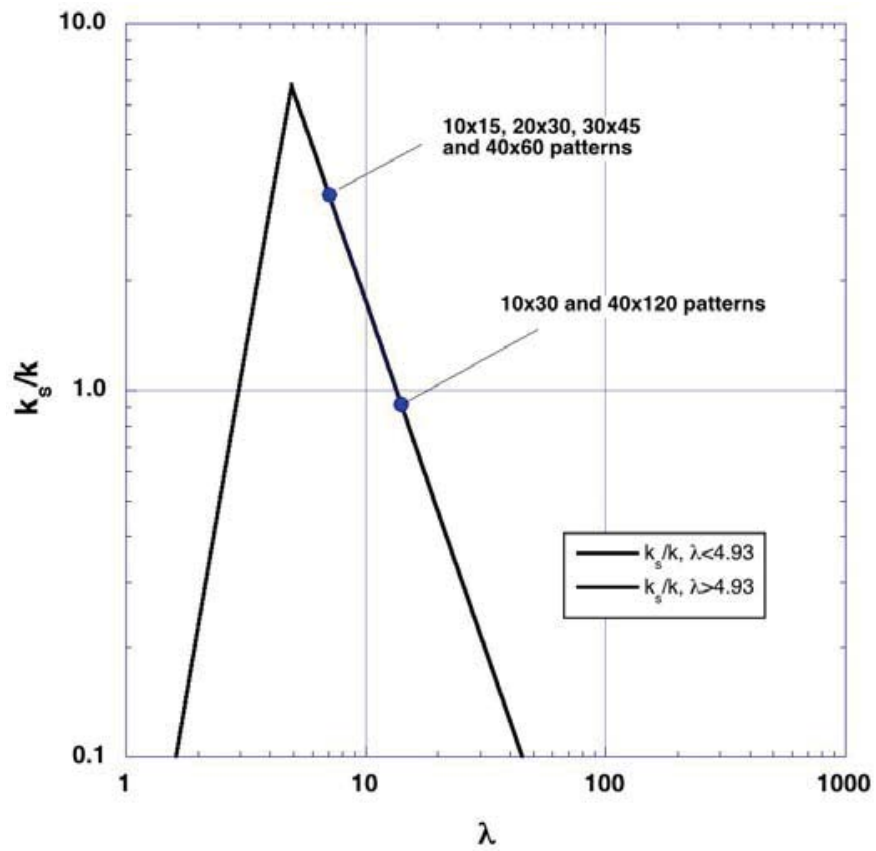

Figure 6. Equivalent sand-grain roughness and Dirling spacing parameters

\section{Sand-grain surface roughness wind tunnel models}

Sand-grain surface roughness was produced by applying an adhesive coating to the SLA resin patterns and then dipping the patterns into a bed of precision-manufactured, spherical glass particles. The particles adhered to the surface of the patterns to create a distributed, sand-grain roughness over the entire pattern (on the hemispheres, the roughness was truncated approximately one inch from the end of the pattern to ensure the roughness elements did not cause binding when removing the model from the mold). The patterns were then hand-worked to remove any obvious surface irregularities (i.e. clumps of glass spheres) and then ceramic models were fabricated from them following the same steps as for smooth-surface models. A resin pattern coated with particles, a finished ceramic model, and closeups of the various surface roughness elements are shown in Figure 7.

The spherical glass particles applied to the models were procured with diameters ranging from 0.0025 in. to 0.0689 in., where the particle sizes were specified according to an ATSM E11:01 standard wire mesh standard (defined by the diameter of a particle which will fit through a mesh sieve). Models are identified according to the 
ATSM designation of the particle size and a listing of the models and roughness parameters is given in Table 4. The "smooth-wall" baseline model roughness, as defined by the roughness of the thermographic phosphor coating is also listed. For the scope of the present study, the sand-grain roughness of a model is simply assumed to be equal to the particle radius. While alternative definitions based on statistical analyses of measured surface roughness height distributions can be found in the literature, the range of roughness considered in this study spans two orders of magnitude and as such it is assumed that the precise definition of the roughness height is a $2^{\text {nd }}$-order consideration.
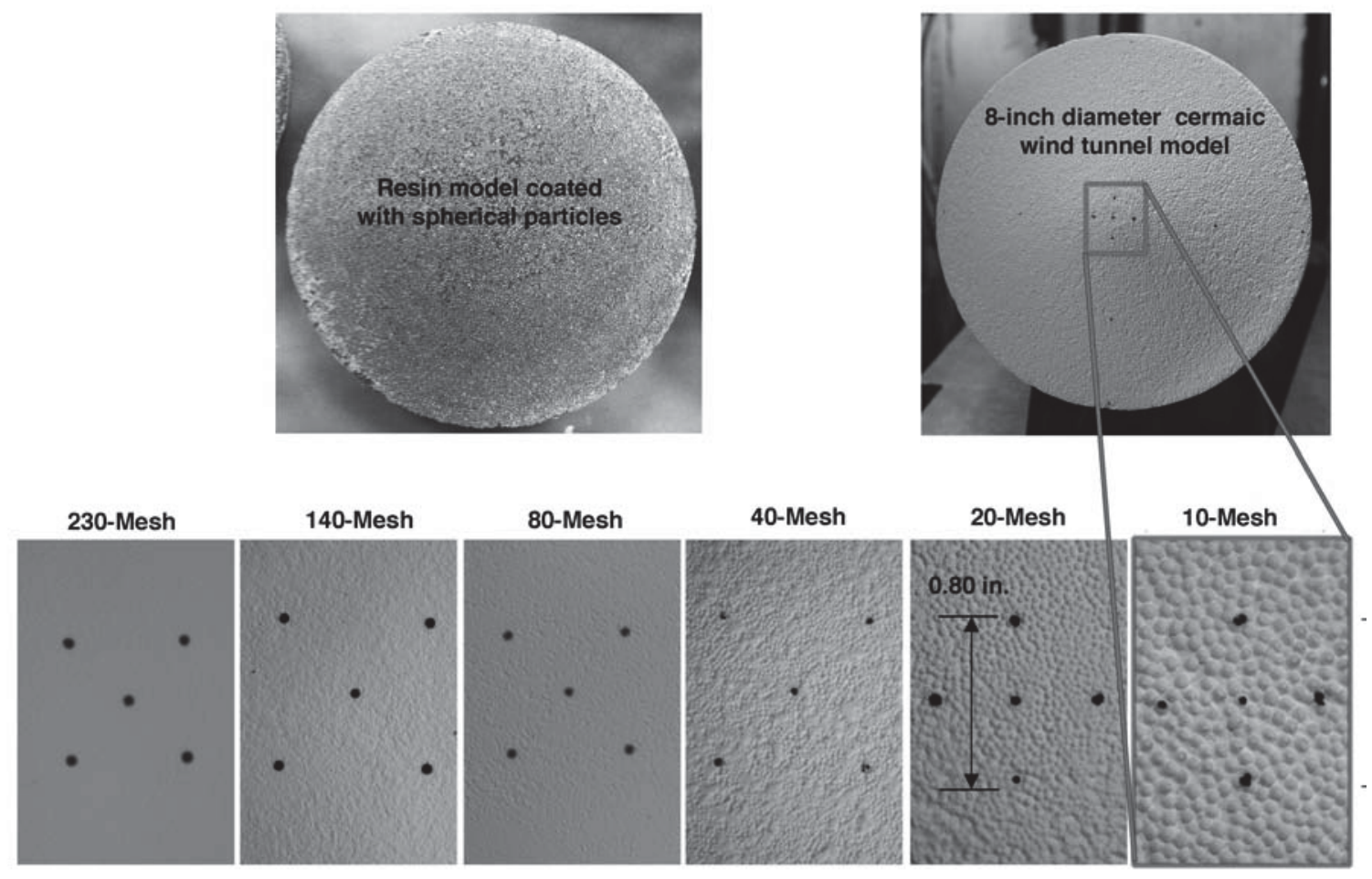

Figure 7. Sand-grain Roughness Layout

Table 4. Sand grain surface roughness model parameters

\begin{tabular}{ccccc}
$\begin{array}{c}\text { ATSM } \\
\text { ID }\end{array}$ & Element & $\begin{array}{c}\text { Diam. } \\
(\mathbf{m m})\end{array}$ & $\begin{array}{c}\text { Diam. } \\
\text { (in) }\end{array}$ & $\begin{array}{c}\boldsymbol{k}_{\text {s }} \\
\text { (in) }\end{array}$ \\
\hline 10-Mesh & hemispherical & 1.7500 & 0.0689 & 0.0344 \\
20-Mesh & hemispherical & 0.8530 & 0.0336 & 0.0168 \\
40-Mesh & hemispherical & 0.4250 & 0.0167 & 0.0084 \\
80-Mesh & hemispherical & 0.1800 & 0.0071 & 0.0035 \\
140-Mesh hemispherical & 0.1060 & 0.0042 & 0.0021 \\
230-Mesh hemispherical & 0.0630 & 0.0025 & 0.0012 \\
Phosphor hemispherical & 0.0254 & 0.0010 & 0.0005 \\
\hline
\end{tabular}

\section{Computational Method}

\section{A. LAURA Flow-Field Solver}

Flow field predictions were performed using the LAURA (Langley Aerothermodynamic Upwind Relaxation Algorithm) code (Ref. 10) to obtain heat-transfer rates for comparisons with the experimental data and boundarylayer parameters for use in correlating the data. LAURA is a three-dimensional, finite-volume solver that includes perfect-gas and non-equilibrium chemistry options, a variety of turbulence models, and ablation and radiative transport capabilities. 
In this study, the perfect-gas air model was used for the wind tunnel predictions. Both laminar and turbulent solutions were generated, with the Cebeci-Smith algebraic model (Ref. 11) being used for the turbulent cases. Solutions were generated on structured, finite-volume multi-block computational grids with a singularity-free nose blocks. Grid adaption to the flow features was performed to align the outer boundary of the grid with the shock and to cluster grid cells near the surface to produce wall cell Reynolds numbers on the order of 1 .

Free-stream conditions were set equal to the tunnel operating conditions, with the wall temperature specified as a constant $300 \mathrm{~K}$. The use of a constant wall temperature is acceptable because the heat-transfer coefficient varies only very slightly over the range of wall temperatures produced in this facility.

\section{B. Computational Validation}

In this study, values for turbulent roughness heating augmentation are defined based on comparisons of the experimental data to computed turbulent heating levels. It is therefore important to establish the accuracy of the computational technique. Relevant comparisons to laminar and turbulent smooth-wall sphere-cone heating data have been performed previously for studies in the LaRC 20-Inch Mach 6 Air Tunnel (Ref. 12) and the Arnold Engineering Development Center (AEDC) Hypervelocity Tunnel 9 (Ref. 13). For laminar conditions, LAURA predictions agreed with experimental data to within the estimated experimental uncertainty, with the exception of small regions around the stagnation point on the windward flank of the heat shield. For turbulent conditions, LAURA predictions were within or slightly below the experimental uncertainty range depending on test conditions. This under-prediction of smooth-wall turbulent cases from past studies is important to consider in comparisons to roughness-augmented turbulent data from this study.

A likely explanation for at least part of these differences is in the specification of the transition onset location. In LAURA, the algebraic turbulence models do not have an inherent transition onset mechanism. A transition onset location can be specified by the user, but lacking a validated and accepted transition criteria for large-cone angle, blunt body flows, the entire flow field is usually assumed to be turbulent, as was the case for this study. However, as was shown in the LaRC test (Ref. 12), the turbulent heating levels on the flank of a large cone-angle blunt body can be dependent on the transition onset location; in general, the farther outboard transition onset is specified to occur, the higher the predicted downstream turbulent heating levels. Thus, if a solution is generated assuming fullyturbulent flow over the entire vehicle, the heating levels will be lower than measured levels for a case where transition occurs downstream of the stagnation point on the conical flank. Presumably this effect is due to the boundary layer not having sufficient running length to reach an equilibrated turbulent profile before reaching the shoulder. This assumption can be supported by noting that comparisons for the AEDC test (Ref. 13) were better at higher free stream Reynolds number - i.e. for cases where the transition onset location was closer to the stagnation point.

\section{Results and Analysis}

\section{A. Test conditions}

Roughness data were obtained in two wind tunnel entries, identified as Test 6971 for the sphere-cone models and Test 6975 for the hemisphere models. Runs were performed at free stream Reynolds numbers of $\operatorname{Re}_{\infty}=3.0 \times 10^{6} / \mathrm{ft}$ to $\operatorname{Re}_{\infty}=8.3 \times 10^{6} / \mathrm{ft}$ with 16 -deg angle-of-attack for the sphere-cone and 0-deg angle-of-attack for the hemisphere. Free stream conditions for the tests are given in Table 5.

Table 5. Nominal Conditions for LaRC 20-Inch Mach 6 Air Tunnel Tests 6791 and 6975

\begin{tabular}{|c|c|c|c|c|c|c|c|c|c|c|c|}
\hline \multirow[b]{2}{*}{$\begin{array}{l}\operatorname{Re}_{\infty} \\
(1 / f t)\end{array}$} & \multirow[b]{2}{*}{$\begin{array}{c}\operatorname{Re}_{\infty} \\
(1 / \mathrm{m})\end{array}$} & \multirow[b]{2}{*}{$\mathrm{M}_{\infty}$} & \multirow[b]{2}{*}{$\begin{array}{c}\mathrm{P}_{\infty} \\
(\mathrm{Pa})\end{array}$} & \multirow[b]{2}{*}{$\begin{array}{l}\mathrm{T}_{\infty} \\
(\mathrm{K})\end{array}$} & \multirow[b]{2}{*}{$\begin{array}{c}\rho_{\infty} \\
\left(\mathrm{kg} / \mathrm{m}^{3}\right)\end{array}$} & \multirow[b]{2}{*}{$\begin{array}{c}\mathrm{U}_{\infty} \\
(\mathrm{m} / \mathrm{s})\end{array}$} & \multirow[b]{2}{*}{$\begin{array}{c}\mathrm{H}_{0}-\mathrm{H}_{300 \mathrm{~K}} \\
(\mathrm{~J} / \mathrm{kg})\end{array}$} & \multicolumn{2}{|c|}{ Hemisphere } & \multicolumn{2}{|c|}{ Sphere-cone } \\
\hline & & & & & & & & $\begin{array}{c}\mathrm{h}_{\mathrm{FR}-\mathrm{hemi}} \\
\left(\mathrm{kg} / \mathrm{m}^{2} / \mathrm{s}\right)\end{array}$ & $\begin{array}{c}\mathrm{q}_{\mathrm{FR}-\mathrm{hemi}} \\
\left(\mathrm{W} / \mathrm{cm}^{2}\right)\end{array}$ & $\begin{array}{c}\mathrm{h}_{\mathrm{FR}-\mathrm{hemi}} \\
\left(\mathrm{kg} / \mathrm{m}^{2} / \mathrm{s}\right)\end{array}$ & $\begin{array}{r}\mathrm{q}_{\mathrm{FR}-\mathrm{hemi}} \\
\left(\mathrm{W} / \mathrm{cm}^{2}\right)\end{array}$ \\
\hline $3.03 \mathrm{E}+06$ & $9.95 \mathrm{E}+06$ & 5.99 & 844.1 & 62.5 & $4.708 \mathrm{E}-02$ & 948.7 & $2.120 \mathrm{E}+05$ & $2.163 \mathrm{E}-01$ & 4.581 & 2.649E-01 & 5.611 \\
\hline $5.04 \mathrm{E}+06$ & $1.65 \mathrm{E}+07$ & 6.02 & 1421.0 & 63.2 & 7.843E-02 & 957.5 & $2.213 \mathrm{E}+05$ & $2.823 \mathrm{E}-01$ & 6.239 & $3.458 \mathrm{E}-01$ & 7.641 \\
\hline $6.63 \mathrm{E}+06$ & $2.18 \mathrm{E}+07$ & 6.04 & 1833.0 & 62.6 & $1.023 \mathrm{E}-01$ & 954.6 & $2.170 \mathrm{E}+05$ & $3.212 \mathrm{E}-01$ & 6.984 & 3.934E-01 & 8.554 \\
\hline $7.46 \mathrm{E}+06$ & $2.45 \mathrm{E}+07$ & 6.04 & 2058.0 & 62.5 & $1.154 \mathrm{E}-01$ & 953.6 & $2.167 \mathrm{E}+05$ & $3.402 \mathrm{E}-01$ & 7.364 & 4.167E-01 & 9.019 \\
\hline $8.34 \mathrm{E}+06$ & $2.74 \mathrm{E}+07$ & 6.03 & 2090.8 & 58.6 & $1.249 \mathrm{E}-01$ & 918.1 & $1.791 \mathrm{E}+05$ & 3.407E-01 & 6.101 & 4.173E-01 & 7.472 \\
\hline
\end{tabular}




\section{B. Heating Data and Comparisons with Predictions}

Data were obtained for each sand-grain and pattern roughness element configuration for each model at all free stream Reynolds number conditions, plus a small number of repeat runs, for a total of more than 100 separate cases. As this data set is too large to be presented in its entirety here, data will be presented for each roughness configuration only at the lowest and highest Reynolds numbers of $\operatorname{Re}_{\infty}=3.0 \times 10^{6} / \mathrm{ft}$ and $8.3 \times 10^{6} / \mathrm{ft}$. Analyses and comparisons presented are based only on centerline values. As these values represent only a small subset of the large, global data set, the results may not be representative of behavior over the entire geometry.

Global aeroheating distributions from the thermographic phosphor measurements and comparisons of centerline data with LAURA laminar and fully-turbulent predictions are shown in Figure 8 and Figure 9 for the sphere-cone with sand-grain roughness, Figure 10 and Figure 11 for the sphere-cone with pattern roughness, and Figure 12 and Figure 13 for the hemisphere with sand-grain roughness. In all cases, the images and line-plots are ordered in terms of increasing sand-grain height, or the for pattern models, by equivalent sand-grain height.

The observed behavior of the data for both the sphere-cone and hemisphere sand-grain roughness cases is consistent and follows expected trends: as the sand-grain roughness height is increased for a given Reynolds number, the transition onset location moves closer to the stagnation point and the turbulent heating levels increase further over the predicted turbulent values.

The sphere-cone pattern roughness data behavior is also generally consistent and follows expected trends. However, there is one discrepancy in that the heating data from 40x120 pattern model $\left(k_{\mathrm{S}}=0.0183\right.$ in. $)$ shows higher augmentation than that of the $20 \times 30$ pattern model $\left(k_{\mathrm{s}}=0.0341 \mathrm{in}\right.$.), when according to the theory presented for equivalent sand-grain roughness heights, the reverse would be expected. With respect to this observation, several points should be considered: 1) The Dirling spacing value for the 20x30 model is close to the inflection point in the functional relationship between $\lambda$ and $k_{\mathrm{S}} / k$ and some uncertainty in the definition there might be expected; 2) other authors have suggested alternative forms for this correlation (e.g. Ref. 14) that may provide a better representation of these data; and 3) the physical roughness height of the 40x120 pattern is greater than the boundary layer height (i.e. $k / \delta>1$ ) in a significant region between the stagnation point and the nose of the sphere-cone, and thus correlations based on the assumption of roughness elements submerged within the boundary layer may not accurately reflect the current data set. 


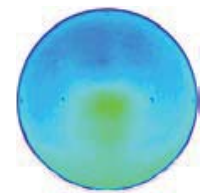

Smooth, Run 1

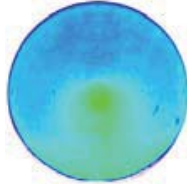

140-Mesh, Run 14

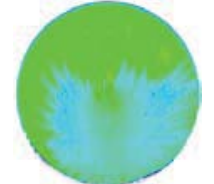

40-Mesh, Run 24

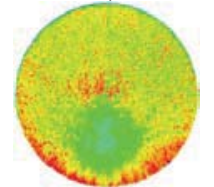

10-Mesh, Run 81

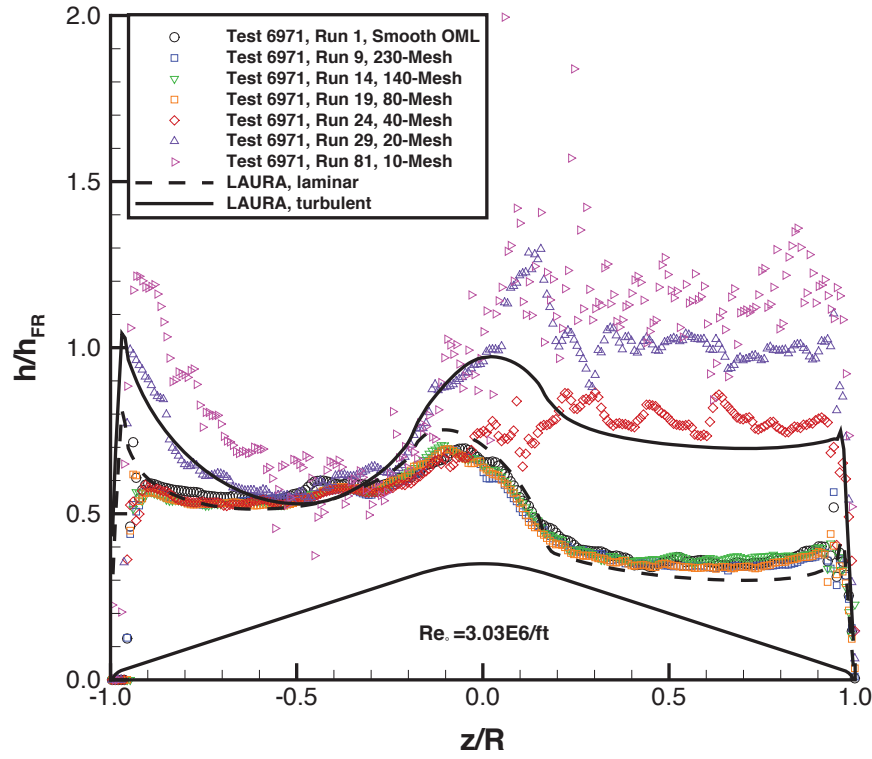

Centerline Heating Distribution

Figure 8. Sphere-cone sand-grain roughness data, $\operatorname{Re}_{\infty}=3.0 \times 10^{6} / \mathrm{ft}, \alpha=16$-deg

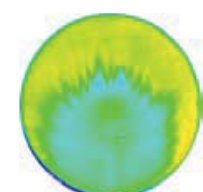

Smooth, Run 7

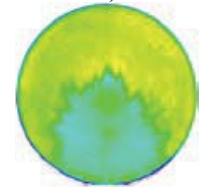

140-Mesh, Run 18

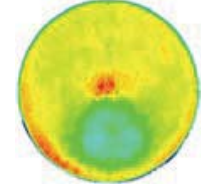

40-Mesh, Run 28

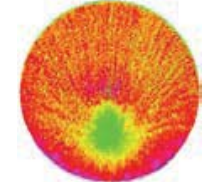

10-Mesh, Run 80

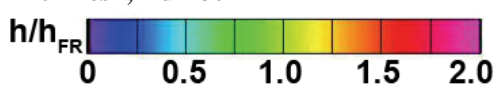

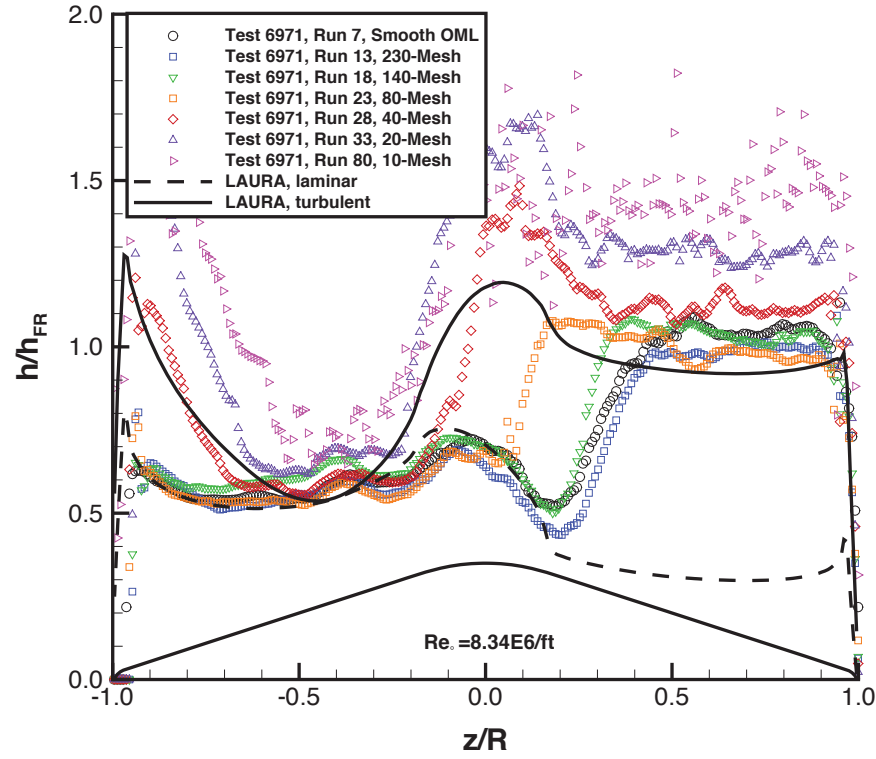

Centerline Heating Distribution

Figure 9. Sphere-cone sand-grain roughness data, $\operatorname{Re}_{\infty}=8.3 \times 10^{6} / \mathrm{ft}, \alpha=16-\mathrm{deg}$ 


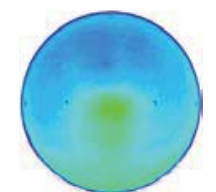

Smooth, Run 1

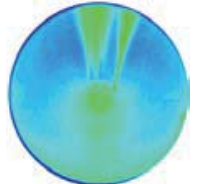

10x15 Pattern, Run 49

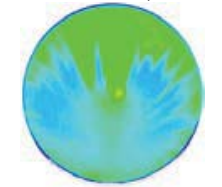

20x30 Pattern, Run 44

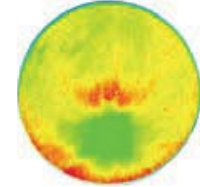

40x60 Pattern, Run 34

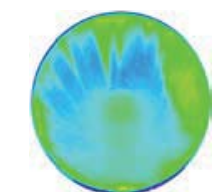

10x30 Pattern, Run 54

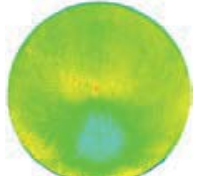

40x120 Pattern, Run 60

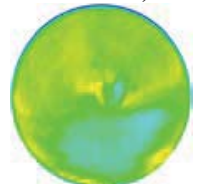

30x45 Pattern, Run 85

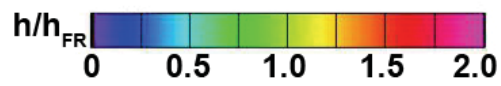

Figure 10. Sphere-cone pattern roughness data, $\operatorname{Re}_{\infty}=3.0 \times 10^{6} / \mathrm{ft}, \alpha=16-\mathrm{deg}$

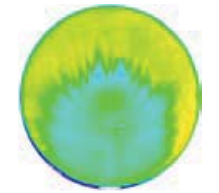

Smooth, Run 7

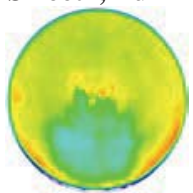

10x15 Pattern, Run 53

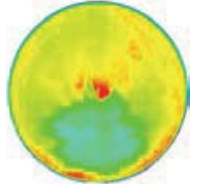

20x30 Pattern, Run 48

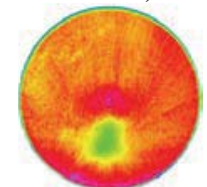

40x60 Pattern, Run 38

\begin{tabular}{rrrrr|r}
$\mathrm{h} / \mathrm{h}_{\mathrm{FR}}$ & & & & & \\
0 & 0.5 & 1.0 & 1.5 & 2.0
\end{tabular}

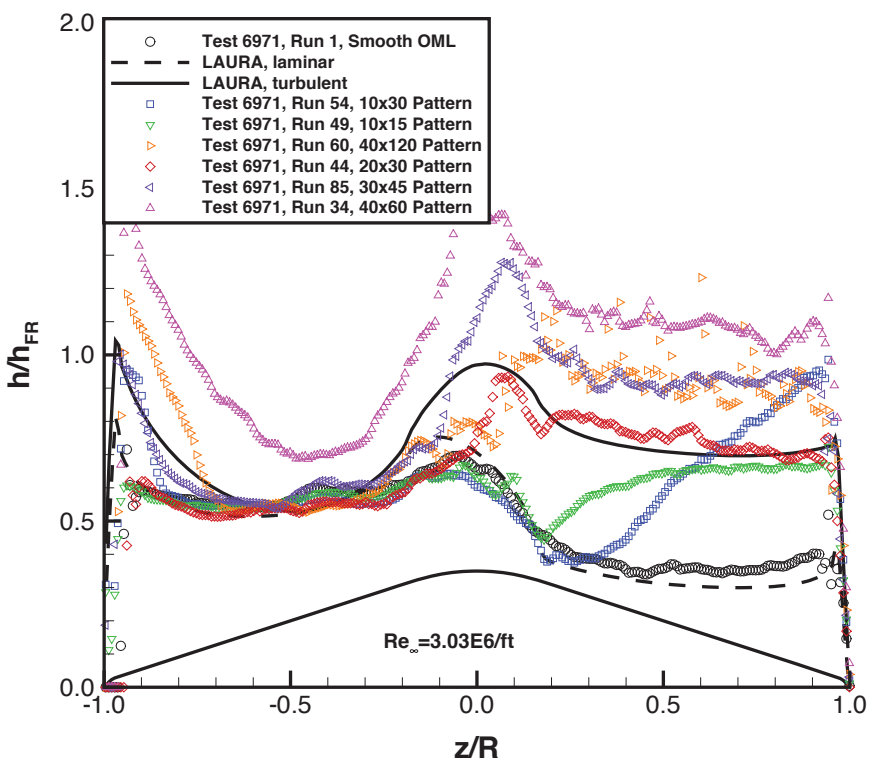

Centerline Heating Distribution

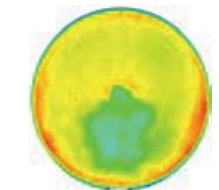

10x30 Pattern, Run 59

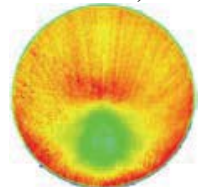

40x120 Pattern, Run 64

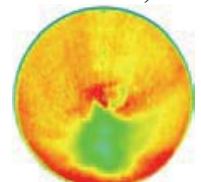

30x45 Pattern, Run 89

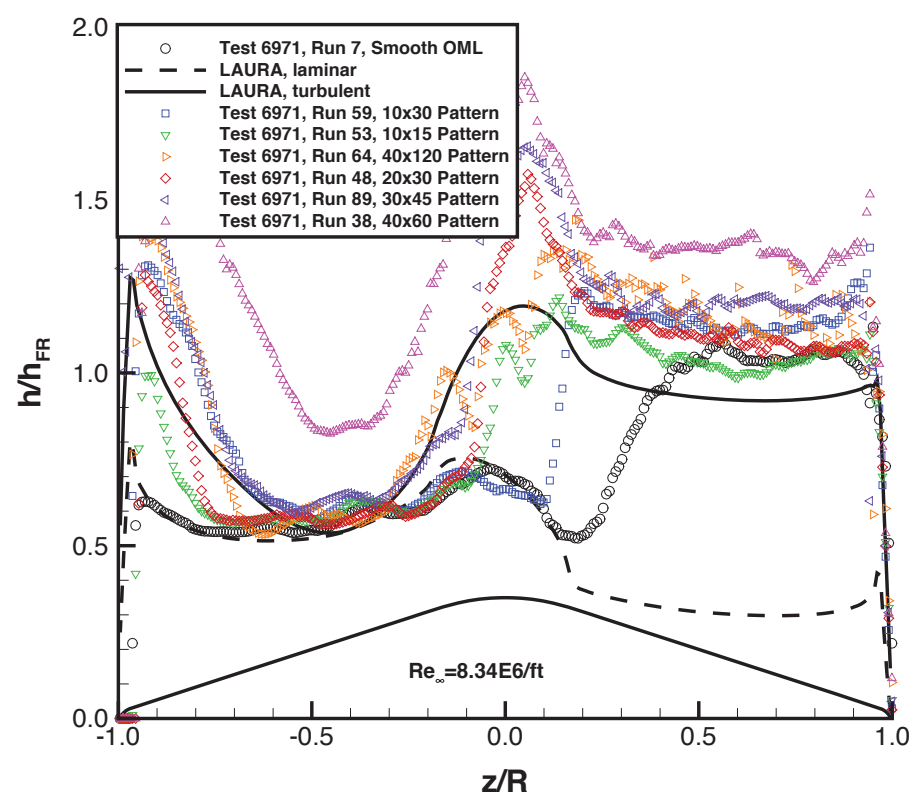

Centerline Heating Distribution

Figure 11. Sphere-cone pattern roughness data, $\operatorname{Re}_{\infty}=8.3 \times 10^{6} / \mathrm{ft}, \alpha=16-\mathrm{deg}$ 


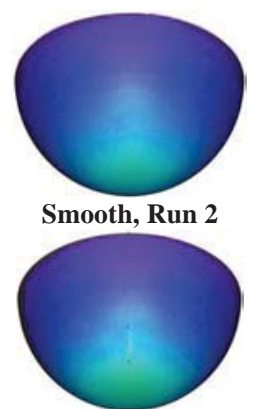

140-Mesh, Run 27

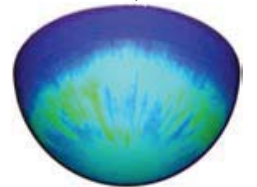

40-Mesh, Run 15

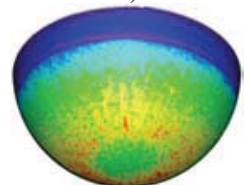

10-Mesh, Run 21

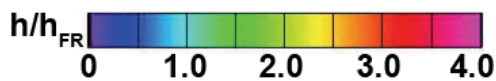

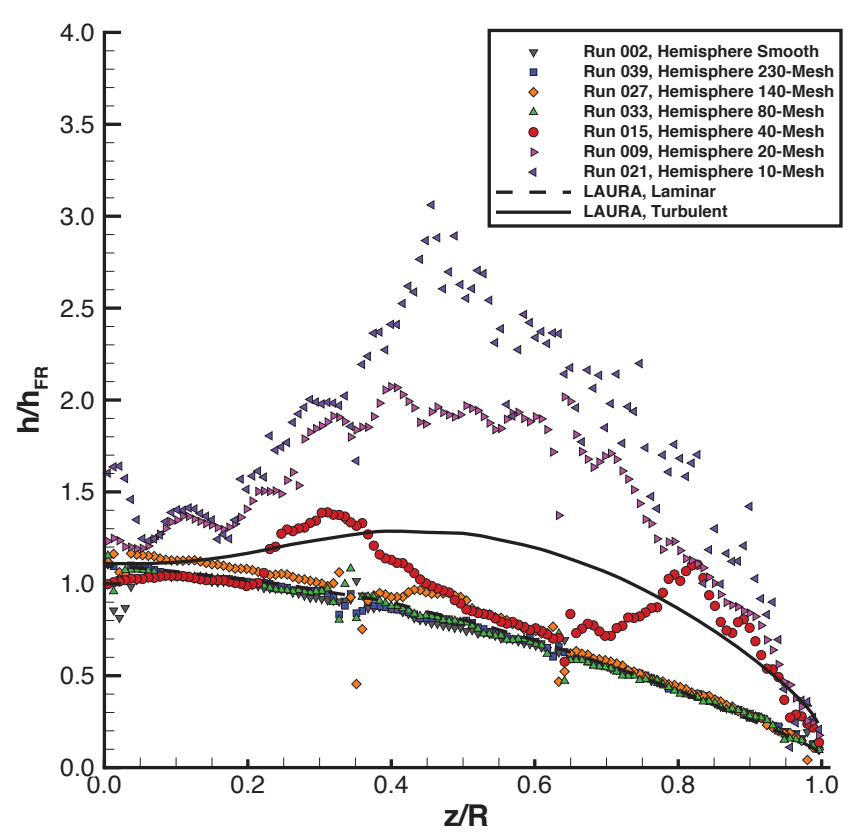

Centerline Heating Distribution

Figure 12. Hemisphere sand-grain roughness data, $\operatorname{Re}_{\infty}=3.0 \times 10^{6} / \mathrm{ft}, \alpha=0$-deg

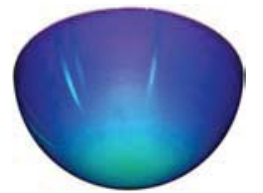

Smooth, Run 8

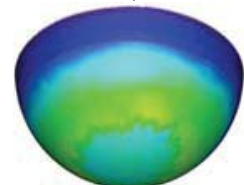

140-Mesh, Run 32

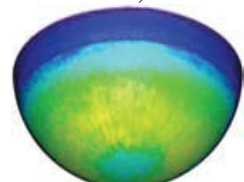

40-Mesh, Run 20

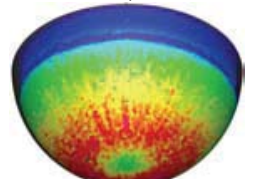

10-Mesh, Run 26

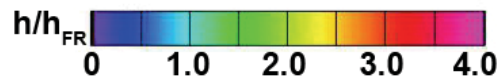

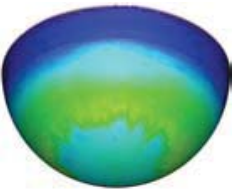

230-Mesh, Run 44

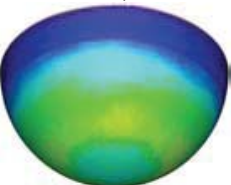

80-Mesh, Run 38

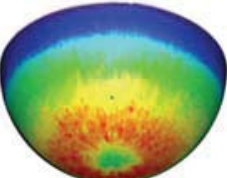

20-Mesh, Run 14

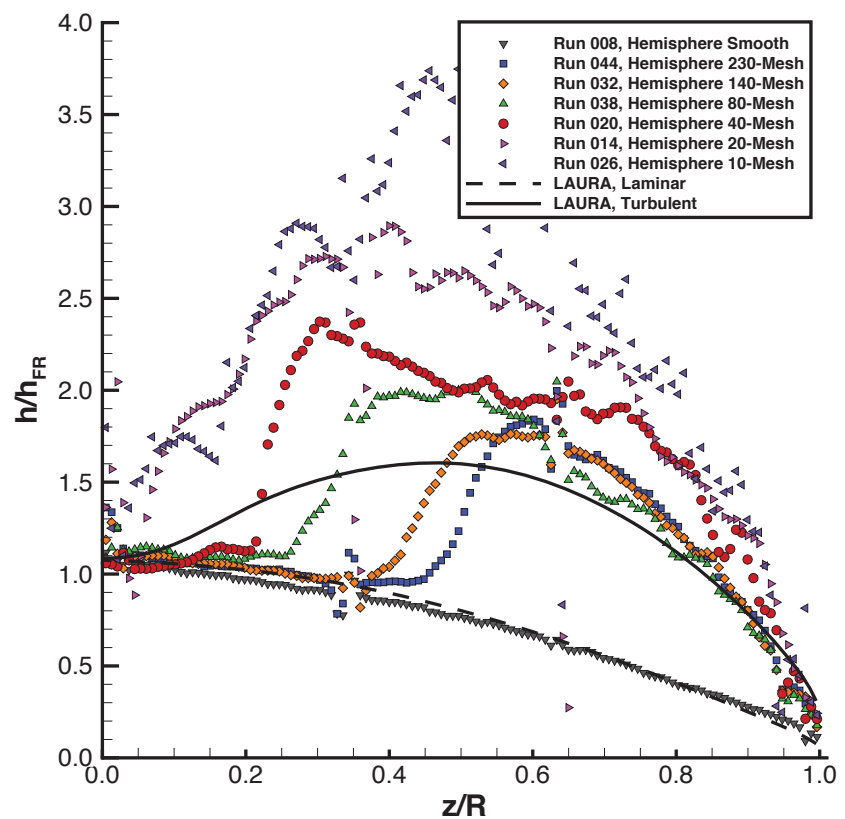

Centerline Heating Distribution

Figure 13. Hemisphere sand-grain roughness data, $\operatorname{Re}_{\infty}=8.3 \times 10^{6} / \mathrm{ft}, \alpha=0$-deg 


\section{Turbulent Roughness Heating Augmentation}

A comparison of the current results with data and correlations from previous studies can be made in terms of the relationship between the roughness Reynolds number $k+$ and turbulent roughness heating augmentation, $h_{\text {rough }} / h_{\text {smooth. }}$. The roughness Reynolds number is defined in terms of the friction velocity as:

(6) $k^{+}=\frac{\rho_{w} U_{\tau} k_{s}}{\mu_{w}}=\frac{k_{s} \sqrt{\tau_{w} / \rho_{w}}}{\mu_{w} / \rho_{w}}$

Centerline $k^{+}$distributions from the LAURA solutions (based on the sand-grain roughness or equivalent) are shown in Figure 14 - Figure 15 for the sphere-cone with sand-grain roughness, Figure 16 - Figure 17 for the spherecone with pattern roughness, and Figure 18 - Figure 19 for the hemisphere with sand-grain roughness. As demonstrated by these figures, the test conditions for this study produced roughness Reynolds numbers spanning two orders of magnitude, from $k^{+} \approx 1$ to 100 . It has been shown (Ref. 15) for incompressible flat-plat flow - and the theory is generally accepted at least qualitatively for compressible flow - that the effects of roughness on the skinfriction (and by analogy, heat-transfer) can be divided into three regimes based on the roughness Reynolds number, each of which is encompassed by the conditions of the current study:

1) For $k^{+}<\sim 10$, the flow is hydraulically smooth. Roughness elements are fully embedded in the laminar sublayer and have minimal affect on the skin-friction

2) For $\sim 10<k^{+}<\sim 70$, the flow is transitionally rough. Roughness elements begin to contribute to skinfriction

3) For $\sim 70<k^{+}$, the flow is fully roughness dominated. The laminar sub-layer disappears, shear stress is directly transmitted to the surface by pressure drag on the roughness elements and skin-friction becomes independent of viscosity.

The definition of the roughness heating augmentation is more subjective. Ideally, the denominator in this term would be based on smooth-wall experimental data at fully-turbulent conditions on the geometry of interest. However, the conditions necessary for smooth-wall fully-turbulent flow are beyond the range of the LaRC 20-Inch Mach 6 Air Tunnel; previous experience from testing at AEDC Hypervelocity Tunnel 9 suggests that a Reynolds number in excess of $\mathrm{Re}_{\infty}=30 \times 10^{6} / \mathrm{ft}$ would be required. Thus, the predicted fully-turbulent heating levels are used in the denominator in place of experimental values.

(7) $\frac{h_{\text {rough }}}{h_{\text {smooth }}}=\frac{\left(h / h_{F R}\right)_{\text {measured }}}{\left(h / h_{F R}\right)_{\text {turbulent }-C F D}}$

As noted previously, the smooth-wall, fully-turbulent CFD predictions using LAURA with the Cebeci-Smith turbulence model are generally lower than measured smooth-wall, turbulent values (especially for cases where the flow field is not fully-turbulent over the entire body) which is may be due to lack of a transition model in the solver and the assumption of fully-turbulent flow over the entire body. Thus, the turbulent roughness heating augmentation definition given by Eq. (7) will introduce a small positive bias to the augmentation values.

Turbulent roughness heating augmentation values were computed for a single, centerline point on each geometry: at $z / R=0.5$ (i.e. on the leeward cone flank) for the sphere-cone and at $z / R=0.7$ for the hemisphere. These locations were selected because the measured heating distributions suggested they were far enough downstream from the transition location to be in the turbulent flow regime. These values are presented in Figure 20 for the sand-grain roughness sphere-cone, in Figure 21 for the pattern roughness sphere-cone, and Figure 22 for the sand-grain roughness hemisphere; also, all the data points are shown together in Figure 23. For clarity, data for laminar and transition conditions (for which the augmentation ratio was much less than 1, are not shown. Additionally, a shaded region is shown on each figure to illustrate an approximate range of historical data sets and correlations, such as from Ref. 16.

For the sphere-cone geometry, heating augmentation levels from approximately $h_{\text {rough }} / h_{\text {smooth }}=1.0$ to 1.8 were observed for sand-grain roughness and from $h_{\text {rough }} / h_{\text {smooth }}=1.0$ to 1.6 for pattern roughness. For the hemisphere geometry, heating augmentation levels between $h_{\text {rough }} / h_{\text {smooth }}=1.0$ to 1.9 were observed. These data exhibit a firstorder, logarithmic relationship between roughness Reynolds number and turbulent roughness heating augmentation

14

American Institute of Aeronautics and Astronautics 
levels such as seen in prior studies. Additionally, while the data exhibit some scatter, they fall within the historical range of data and correlations.

Because of the limitations noted previously with respect to the assumption in the predictions of fully-turbulent flow over the entire and the selection of only a single, centerline data point for comparisons rather than values over the whole body, these results should be considered more qualitative than quantitative. In theory, a more accurate augmentation ratio could be defined by using the current data set to develop a rough-wall boundary-layer transition criteria for use in the LAURA code. A transition criteria would then allow the onset of transition and the development of fully-turbulent flow to be included in the flow-field solution, making for a more appropriate comparison between data and predictions. And given that the data sets are global, comparisons could be made for all points on the body, not just the centerline, to provide a statistically-valid comparison set. However, such work is beyond the scope of the initial analysis presented here.

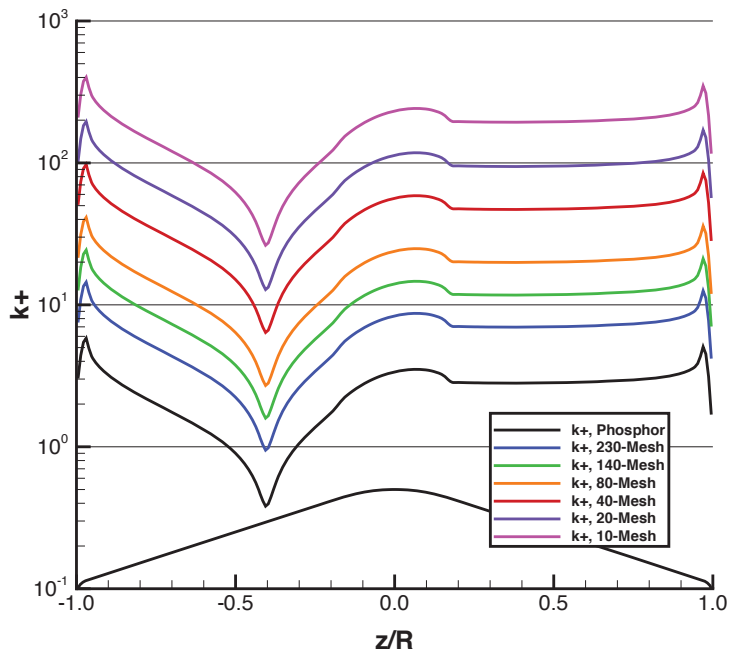

Figure 14. Sphere-cone sand-grain k+ distributions, $\operatorname{Re}_{\infty}=3.0 \times 10^{6} / \mathrm{ft}$

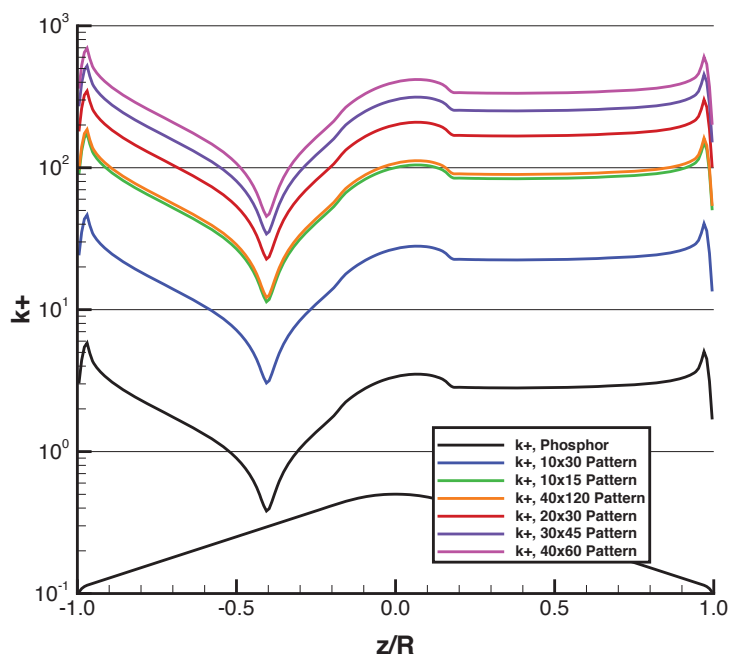

Figure 16. Sphere-cone pattern $k+$ distributions, $\operatorname{Re}_{\infty}=3.0 \times 10^{6} / \mathrm{ft}$

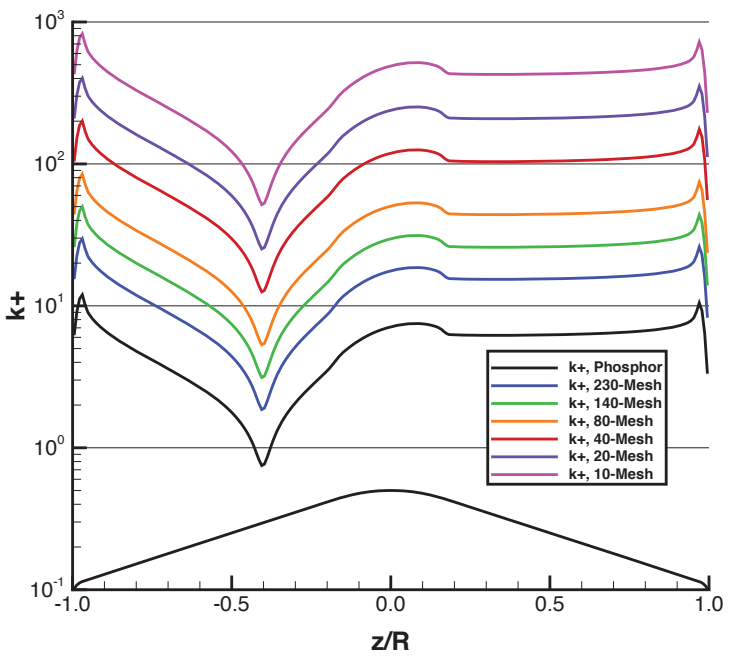

Figure 15. Sphere-cone sand-grain $\mathrm{k}+$ distributions, $\operatorname{Re}_{\infty}=8.3 \times 10^{6} / \mathrm{ft}$

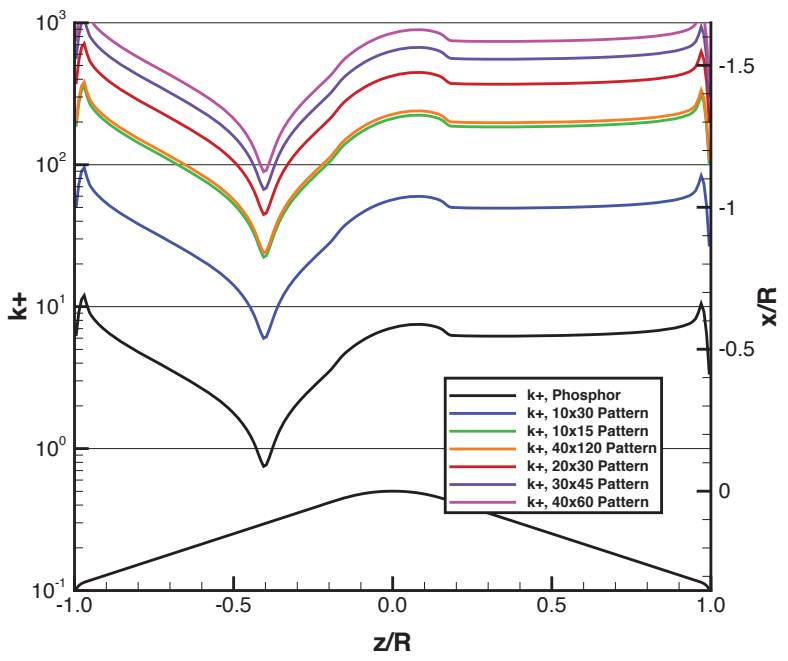

Figure 17. Sphere-cone pattern k+ distributions, $\operatorname{Re}_{\infty}=8.3 \times 10^{6} / \mathrm{ft}$ 


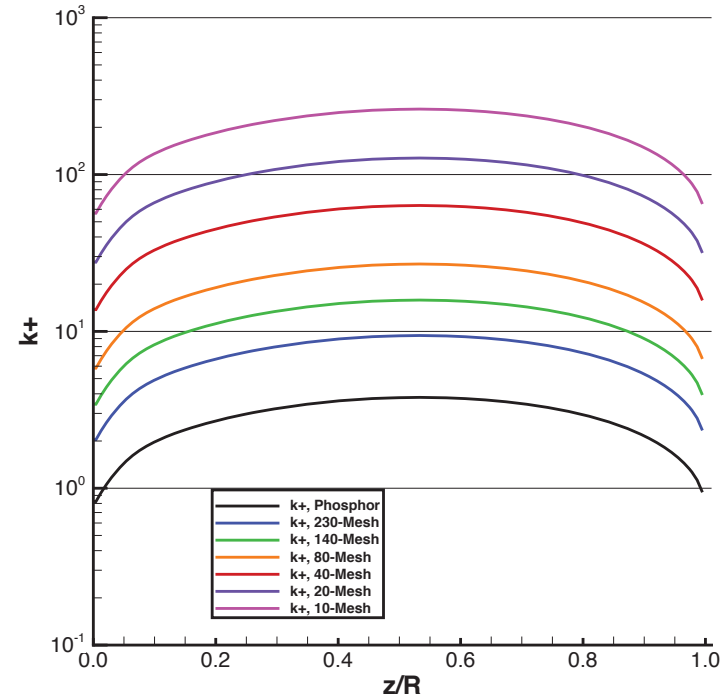

Figure 18. Hemisphere sand-grain k+ distributions, $\operatorname{Re}_{\infty}=3.0 \times 10^{6} / \mathrm{ft}$

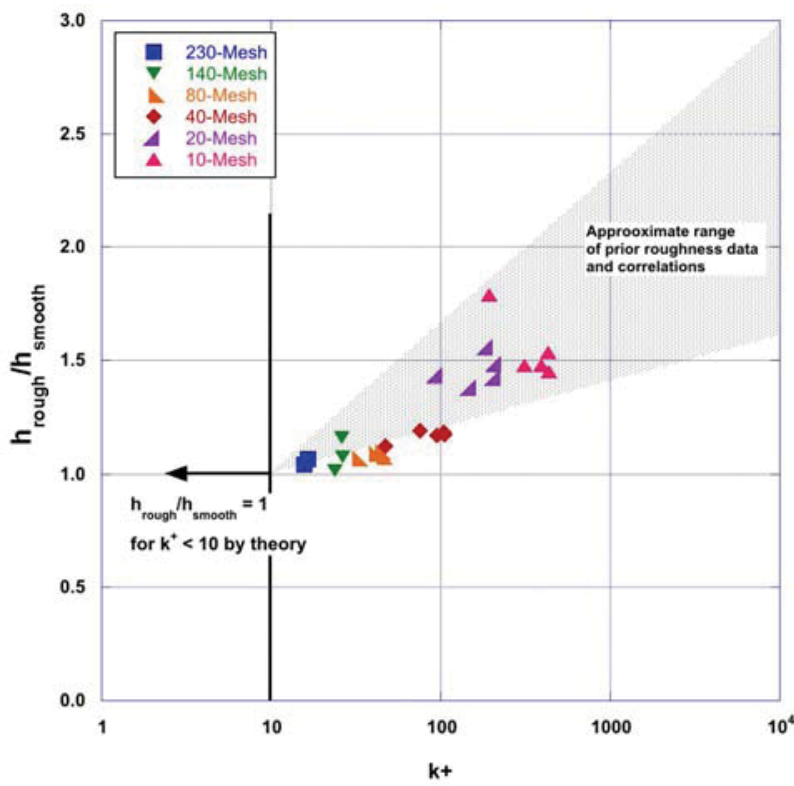

Figure 20. Sphere-cone sand-grain roughness augmentation (at $z / R=0.5$ )

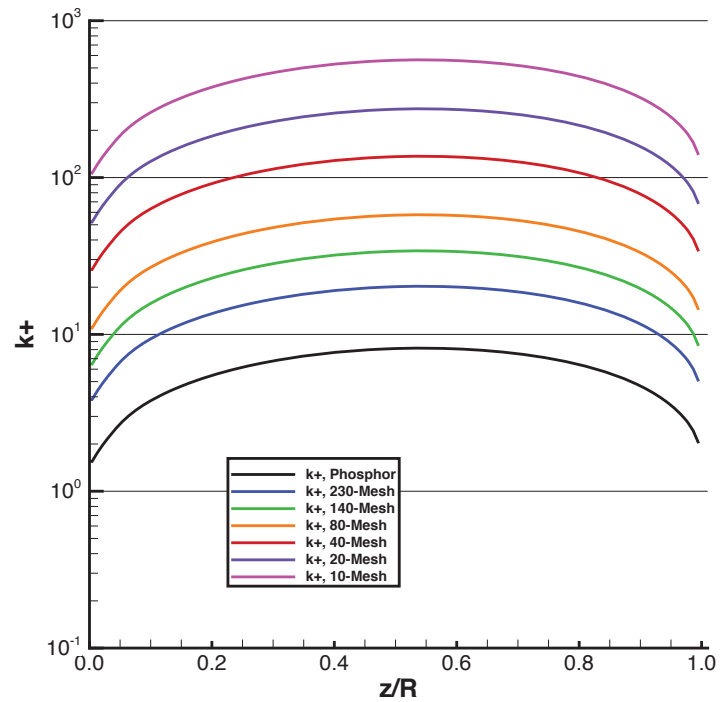

Figure 19. Hemisphere sand-grain k+ distributions, $\operatorname{Re}_{\infty}=8.3 \times 10^{6} / \mathrm{ft}$

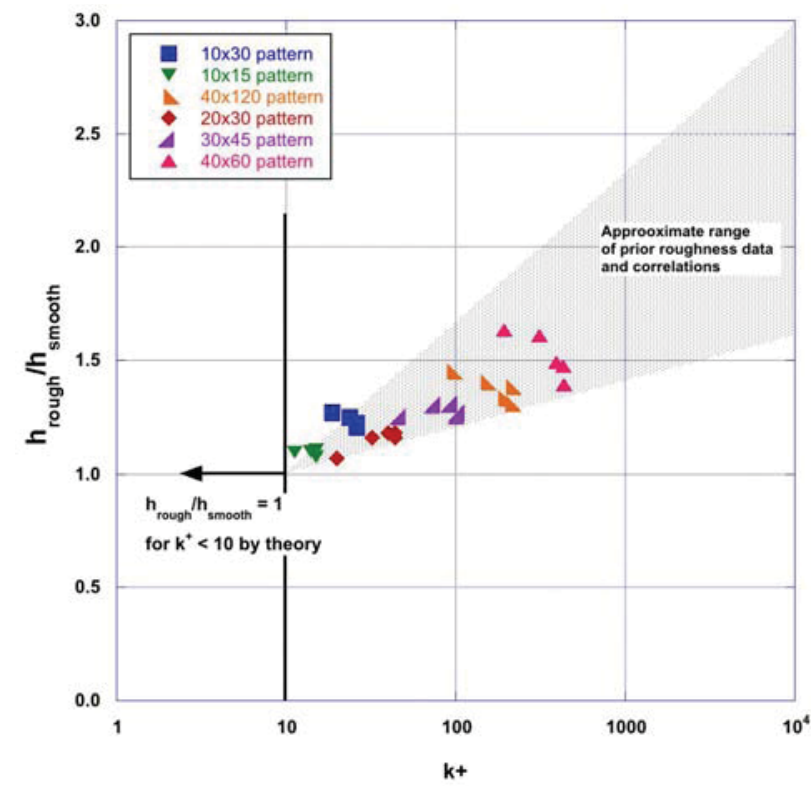

Figure 21. Sphere-cone pattern roughness augmentation $($ at $z / R=0.5)$ 


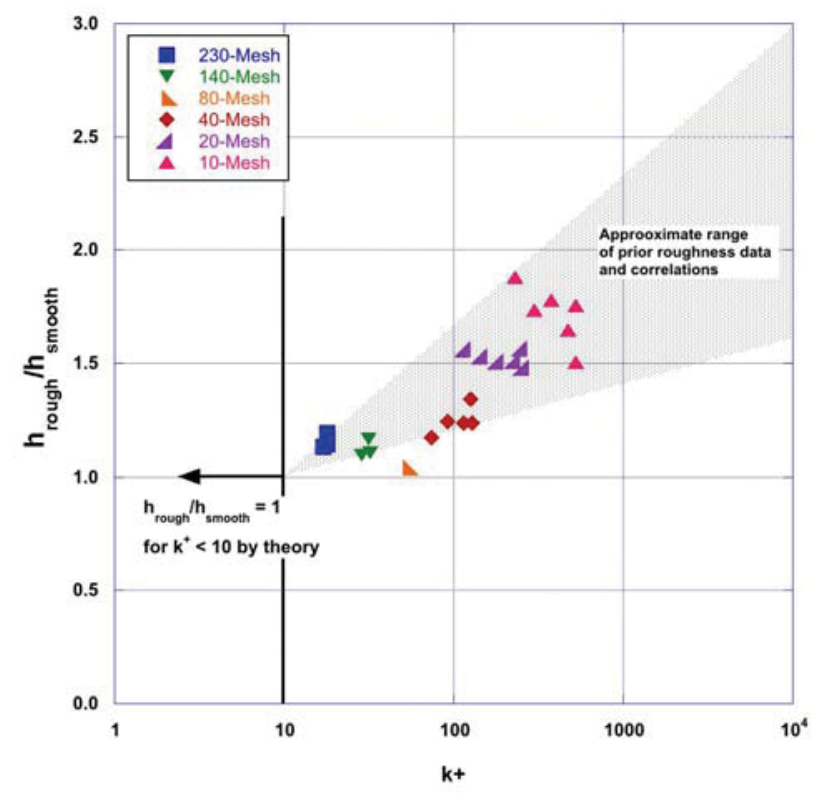

Figure 22. Hemisphere sand-grain roughness augmentation (at $z / R=\mathbf{0 . 7 0})$

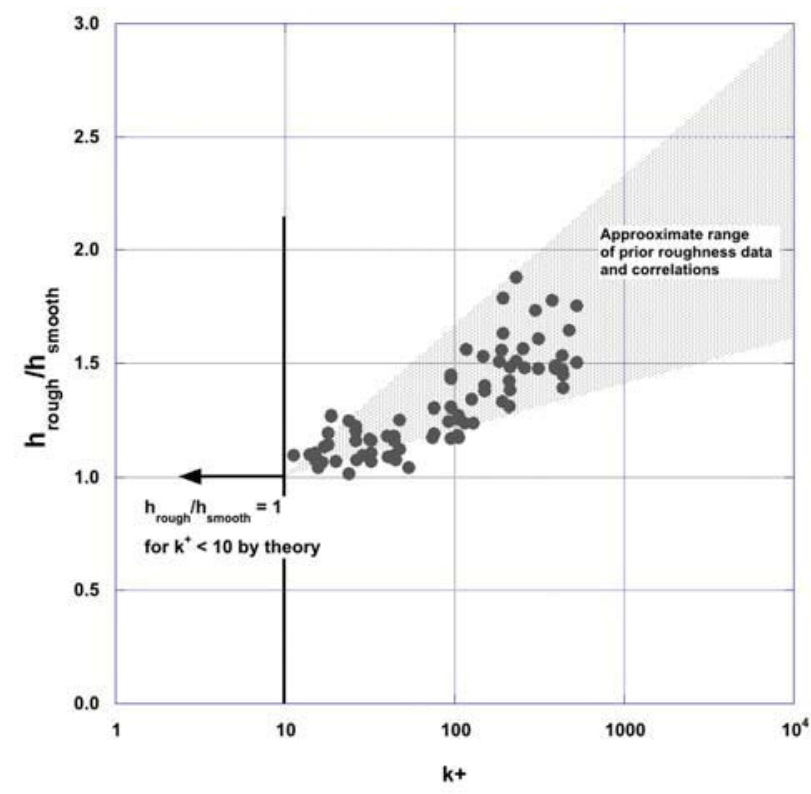

Figure 23. Roughness augmentation (all data)

\section{Roughness Effects on Transition}

As can be seen in the previously-shown comparisons between predicted and measured heating levels, distributed roughness has a direct influence on the location at which boundary-layer transition occurs. The ability to predict where distributed roughness causes transition to begin is of value both for vehicle design purposes and for the development of turbulent roughness heating augmentation correlations. A correlation for transition onset in terms of boundary-layer parameters and roughness height has been given in Ref. 17:

(8)

$$
\left[\operatorname{Re}_{\theta}\left(\mu_{e} / \mu_{w}\right)\right]_{t r}= \begin{cases}500, & \text { for: }\left(\operatorname{Re}_{k} / \operatorname{Re}_{\theta}\right)\left(\mu_{e} / \mu_{w}\right)<0.5 \\ 10 \exp \left\{\log (250)-\log \left[\left(\operatorname{Re}_{k w} / \operatorname{Re}_{\theta}\right)\left(\mu_{w} / \mu_{e}\right)\right]\right\}, & \text { for: } 0.5<\left(\operatorname{Re}_{k} / \operatorname{Re}_{\theta}\right)\left(\mu_{e} / \mu_{w}\right)<2.5 \\ 100, & \text { for }:\left(\operatorname{Re}_{k} / \operatorname{Re}_{\theta}\right)\left(\mu_{e} / \mu_{w}\right)>2.5\end{cases}
$$

where

(9) $\operatorname{Re}_{\theta}=\frac{\rho_{e} U_{e} \theta}{\mu_{e}}$, momentum thickness Reynolds number

and

(10) $\operatorname{Re}_{k w}=\frac{\rho_{k} U_{k} k_{s}}{\mu_{w}}$, roughness Reynolds number

The first region of the correlation corresponds to a "smooth-wall" upper limit for transition and the last region corresponds to a rough wall lower limit. Between these two regions, the slope varies linear on a log-log scale and this function can be rearranged in terms of the critical transition roughness Reynolds number:

(11) $\left[\operatorname{Re}_{k w}\right]_{t r}=250$

Centerline transition onset locations were determined at each free stream Reynolds number for all the geometries. These values are plotted against the correlation of Eq. (8) in Figure 24 for the sand-grain roughness sphere-cone, Figure 25 for the pattern roughness sphere-cone, and Figure 26 for the sand-grain roughness 
hemisphere; also all data points are plotted together in Figure 27. The data match the general trends of the transition correlation, including the upper smooth-wall and lower rough-wall limits and the log-log variation in the roughness transition regime. The scatter of the data shown is greater than the uncertainty bounds given in Ref. 17, however this initial analysis was limited to only centerline transition. A complete analysis of the transition onset location over the entire surface of the models, not just the centerline, will be required to develop a statistically-valid correlation for this data set.

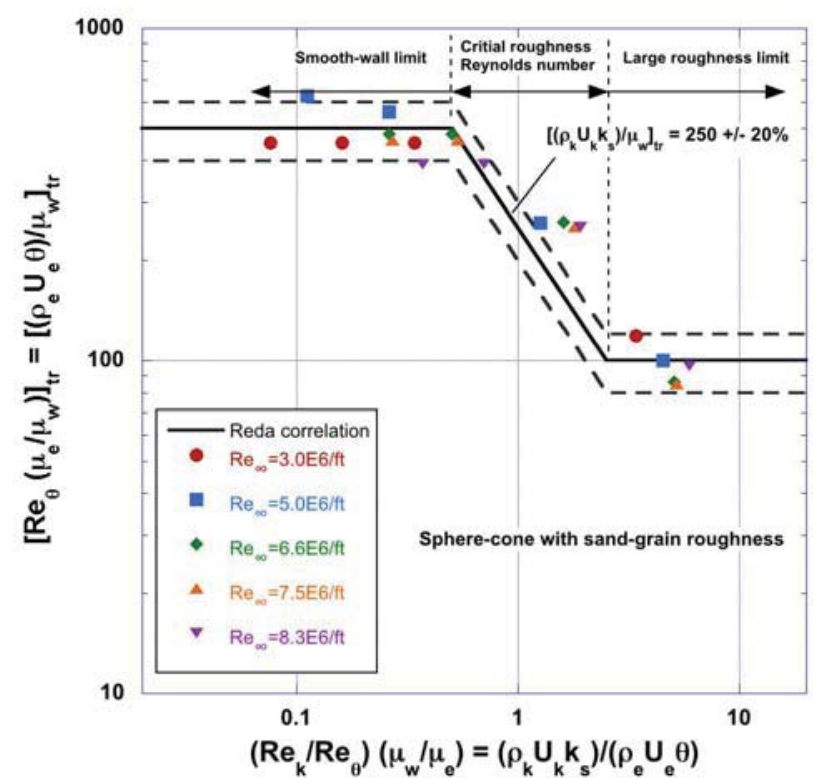

Figure 24. Sphere-cone sand-grain roughness transition onset

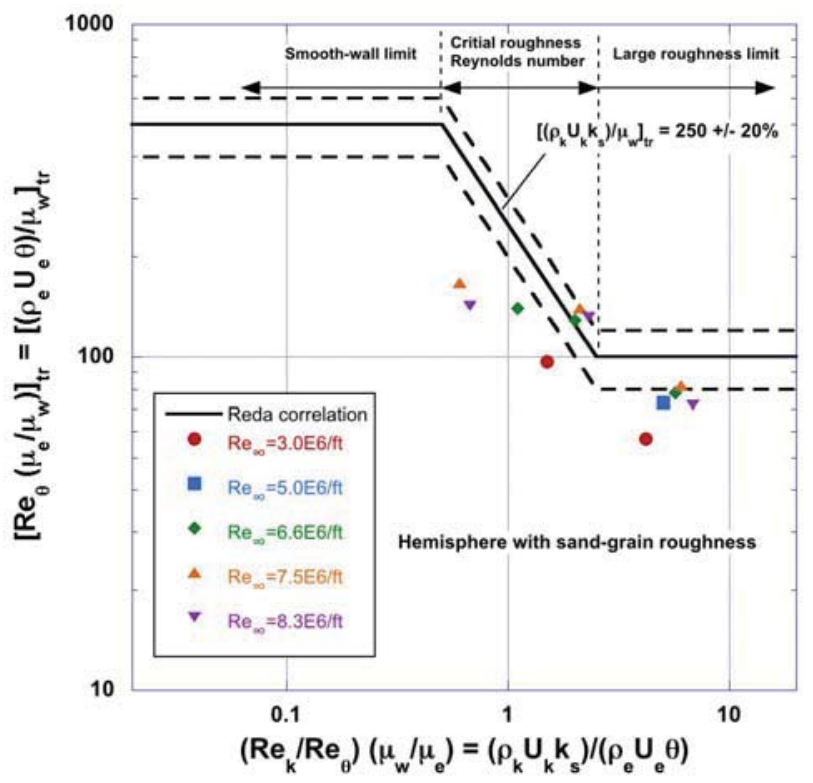

Figure 26. Hemisphere sand-grain roughness transition onset

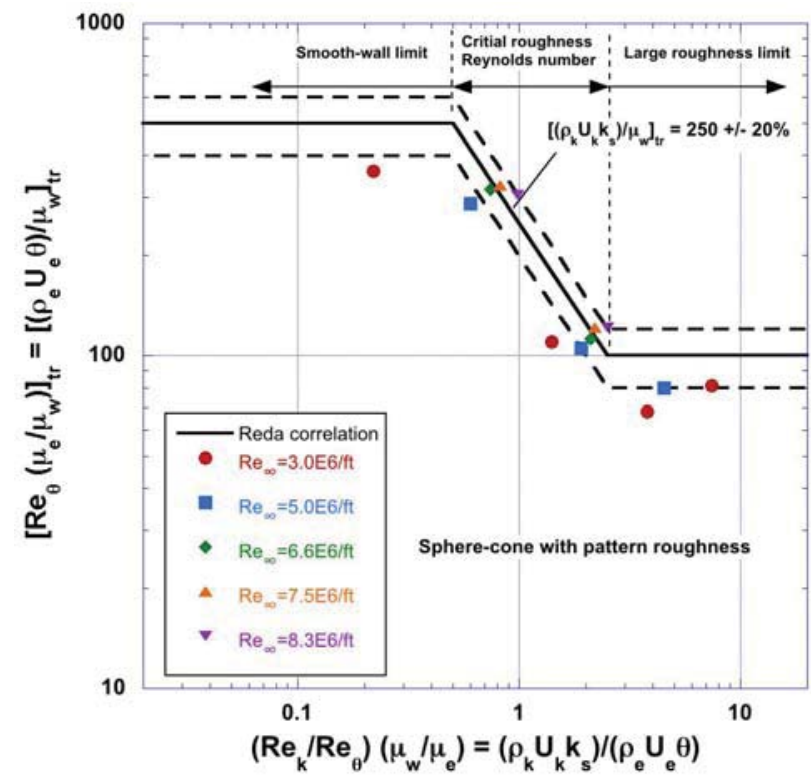

Figure 25. Sphere-cone pattern roughness transition onset

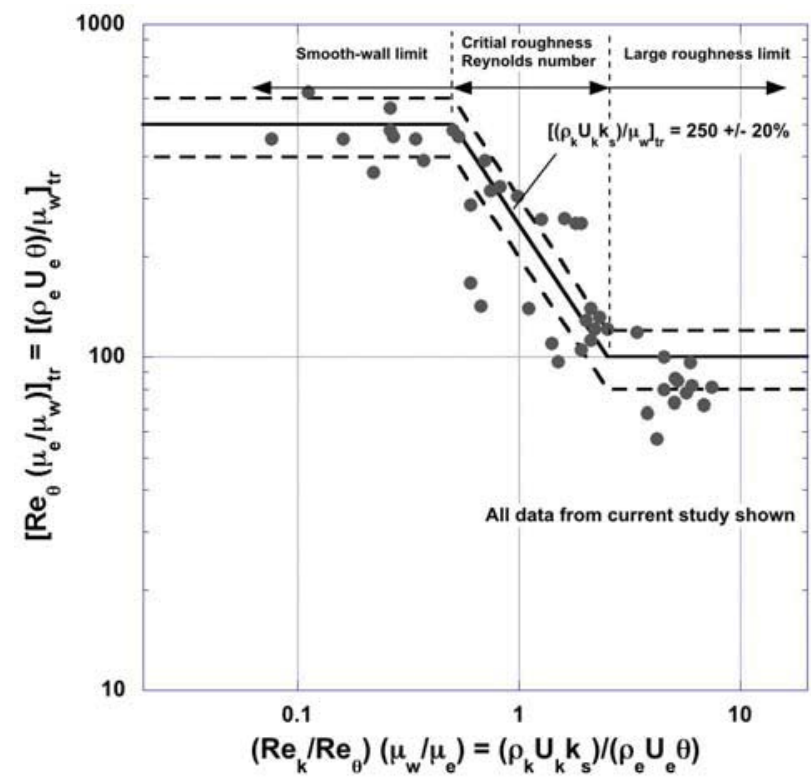

Figure 27. Transition onset (all data) 


\section{Summary}

Roughness-augmented data on boundary-layer transition and turbulent heating have been obtained through testing of models with distributed sand-grain and pattern roughness at hypersonic conditions. Testing was conducted on sphere-cone and hemisphere geometries at free stream Reynolds numbers of $\operatorname{Re}_{\infty}=3.0 \times 10^{6} / \mathrm{ft}$ to $\operatorname{Re}_{\infty}$ $=8.3 \times 10^{6} / \mathrm{ft}$, which produced laminar, transitional and turbulent flow conditions. The models had physical roughness heights from 0.012-in. to 0.034-in, which produced roughness Reynolds numbers spanning two orders of magnitude, from $k^{+} \approx 1$ to 100 . This range encompassed flow regimes from roughness having no effects to fully roughness-dominated flows.

Turbulent heating augmentation levels due to roughness exhibited a logarithmic dependency on the roughness Reynolds number with values ranging between $h_{\text {rough }} / h_{\text {smooth }}=1.0$ to 1.9 , which is consistent with the range of data and correlation in the literature. The influence of roughness on transition was analyzed in terms of boundary-layer parameters $\left(\mathrm{Re}_{\theta}\right.$ and $\left.\mathrm{Re}_{\mathrm{kw}}\right)$ and roughness height. The data exhibited similar behavior to classical transition correlation, including upper smooth-wall and lower rough-wall limits on transition and a log-log dependency between these bounds.

\section{References}

1. Schneider, S. P., "Effects of Roughness on Hypersonic Boundary-Layer Transition," Journal of Spacecraft and Rockets, Vol. 45, No. 2, March-April 2008, pp. 193-209.

2. Schneider, S. P., "Summary of Hypersonic Boundary-Layer Transition Experiments on Blunt Bodies with Roughness," Journal of Spacecraft and Rockets, Vol. 45, No. 6, November-December 2008, pp. 1090-1105.

3. Micol, J. R. "Langley Aerothermodynamic Facilities Complex: Enhancements and Testing Capabilities," AIAA Paper 980147, 36th AIAA Aerospace Sciences Meeting and Exhibit, Reno, NV, January 12-15, 1998.

4. Buck, G. M., "Surface Temperature/Heat Transfer Measurement Using a Quantitative Phosphor Thermography System," AIAA Paper 91-0064, January 1991.

5. Merski, N. R., "Global Aeroheating Wind-Tunnel Measurements Using Improved Two-Color Phosphor Thermography Methods, Journal of Spacecraft and Rockets, Vol. 36, No. 2, pp. 160-170, March-April 1999.

6. Fay, J. A., and Riddell, F. R., "Theory of Stagnation Point Heat Transfer in Dissociated Air," Journal of Aeronautical Sciences, Vol. 25, No. 2., pp. 73-85, February 1958.

7. Buck, G. M., "Rapid Model Fabrication and Testing for Aerospace Vehicles," AIAA Paper 2000-0826, 38th AIAA Aerospace Sciences Meeting and Exhibit, Reno, NV, January 10-13, 2000.

8. Berry, S. A., Hamilton, H. H., and Wurster, K. E., "Effect of Computational Method on Discrete Roughness Correlations for Shuttle Orbiter," Journal of Spacecraft and Rockets, Vol. 43, No. 4, July-August 2006, pp. 842-852.

9. Dirling, R. B., “A Method for Computing Roughwall Heat Transfer Rates on Reentry Nosetips,” AIAA Paper 1973-0763, AIAA $8^{\text {th }}$ Thermophysics Conference, Palm Springs, CA., July 16-18, 1973.

10. Mazaheri, A., Gnoffo, P. A., Johnston, C. O, and Kleb, B., “LAURA Users Manual: 5.5-65135,” NASA TM-2013-217800, February 2013.

11. Cebeci, T. and Smith, A. M. O., "Calculation of Compressible Adiabatic Turbulent Boundary Layers," AIAA Paper 19690687, AIAA Fluid and Plasma Dynamics Conference, San Francisco, CA, June 16-18, 1969.

12. Hollis, B. R. and Liechty, D. S., "Transition Due to Heat-Shield Cavities on a Mars Entry Vehicle," Journal of Spacecraft and Rockets, Vol. 43, No. 2, March-April 2006, pp. 354-366.

13. Hollis, B. R. and Collier, A. S., "Turbulent Aeroheating Testing of Mars Science Laboratory Entry Vehicle," Journal of Spacecraft and Rockets, Vol. 45, No. 3, May-June 2008, pp. 417-427.

14. Sigal, A. and Danberg, J. E., "New Correlation of Roughness Density Effect on the Turbulent Boundary Layer", AIAA Journal, Vol. 28, No. 3, March 1990, pp. 554-556.

15. Nikuradse, J., "Laws of Flow in Rough Pipes," NACA TM-1292, Nov. 1950.

16. Holden, M. S., Mundy, E. P. and MacLean, M., "Heat Transfer Measurements to Examine Surface Roughness and Blowing Effects in Hypersonic Flows," AIAA Paper 2011-0760, AIAA 49 ${ }^{\text {th }}$ Aerospace Sciences Meeting and Exhibit, Orlando, FL., January 4-7, 2011.

17. Reda, D. C., Wilder, M. C., Bogdanoff, D. W. and Prabhu, D. K., Transition Experiments on Blunt Bodies with Distributed Roughness in Hypersonic Free Flight," Journal of Spacecraft and Rockets, Vol. 45, No. 2, March-April 2008, pp. $210-215$. 